\title{
Marine microplastics as vectors of major ocean pollutants and its hazards to the marine ecosystem and humans
}

\author{
Tan Suet May Amelia', Wan Mohd Afiq Wan Mohd Khalik', ${ }^{1,2}$, Meng Chuan Ong ${ }^{1,3}$, Yi Ta Shao ${ }^{4,5^{*}}$, \\ Hui-Juan Pan ${ }^{6,7^{*}}$ and Kesaven Bhubalan ${ }^{1,2,3,8,9^{*}}$ (D)
}

\begin{abstract}
Microplastic pollutes water, land, air, and groundwater environments not only visually but also ecologically for plants, animals, and humans. Microplastic has been reported to act as vectors by sorbing pollutants and contributing to the bioaccumulation of pollutants, particularly in marine ecosystems, organisms, and subsequently food webs. The inevitable exposure of microplastic to humans emphasises the need to review the potential effects, exposure pathways, and toxicity of microplastic toward human health. Therefore, this review was aimed to reveal the risks of pollutant sorption and bioaccumulation by microplastic toward humans, as well as the dominant types of pollutants sorbed by microplastic, and the types of pollutants that are bioaccumulated by microplastic in the living organisms of the marine ecosystem. The possible factors influencing the sorption and bioaccumulation of pollutants by microplastic in marine ecosystems were also reviewed. The review also revealed the prevailing types of microplastic, abundance of microplastic, and geographical distribution of microplastic in the aquatic environment globally. The literature review revealed that microplastic characteristics, chemical interactions, and water properties played a role in the sorption of pollutants by microplastic. The evidence of microplastic posing a direct medical threat to humans is still lacking albeit substantial literature has reported the health hazards of microplasticassociated monomers, additives, and pollutants. This review recommends future research on the existing knowledge gaps in microplastic research, which include the toxicity of microplastic, particularly to humans, as well as the factors influencing the sorption and bioaccumulation of pollutants by microplastic.
\end{abstract}

Keywords: Adsorption, Bioaccumulation, Contaminant, Microplastic, Pollutant, Vector

\section{Introduction}

The plastic industry began in the 1920s and grew rapidly since the 1940s. In 2014, the global plastic output has been 20 times that of 1964 (Neufeld et al. 2016). Globally, the annual production of 330 and 360 million metric tons was recorded for 2016 and 2018, respectively

\footnotetext{
* Correspondence: itshao@mail.ntou.edu.tw; hjpan_siraya@mail.ntou.edu.tw; kesaven@umt.edu.my

${ }^{4}$ Institute of Marine Biology, National Taiwan Ocean University, Keelung 20224, Taiwan

${ }^{6}$ Institute of Earth Sciences, College of Ocean Science and Resource, National Taiwan Ocean University, Keelung 20224, Taiwan

${ }^{1}$ Faculty of Science and Marine Environment, Universiti Malaysia Terengganu, 21030 Kuala Nerus, Terengganu, Malaysia

Full list of author information is available at the end of the article
}

(PlasticsEurope 2017; PlasticsEurope 2019). The annual plastic production is still increasing despite the increased awareness of plastic pollution and efforts to mitigate its pollution. An estimated 275 million metric tons of landbased plastic waste from 192 coastal countries resulted in 4.8 to 12.7 million metric tons entering the ocean in 2010 (Jambeck et al. 2015). Moreover, the degradation and the fragmentation of marine plastic litter lead to the formation of hazardous secondary microplastic in the ocean. In terms of microplastic waste, 60 to 99 million metric tons was generated in 2015 (Lebreton and Andrady 2019). In terms of stray waste alone, roughly six and three million metric tons of macroplastic and 
microplastic, respectively, were lost to the environment in 2015 (Ryberg et al. 2019). The microplastic pollution reported in the literature chiefly refers to the visible or observable presence of microplastic in the food sources, the above-significant levels of microplastic concentrations in the ecosystems, and the risks of microplastic to the environment and public health (Abbasi et al. 2018; Akarsu et al. 2020; Alimi et al. 2018). The presence of most manmade substances in the environment, though inevitable, requires critical attention when their overpresence presents as pollution, with threats and negative implications. In order to challenge the problem of microplastic pollution, it is imperative to recognise the source, transportation, degradation, sink, and consequences of microplastic pollution.

Microplastic is a ubiquitous occurrence in terrestrial, freshwater, and marine environments (Yu et al. 2019a). The sources of microplastic include wastewater treatment plants, landfills, irrigation, agricultural fields, industrial effluent, and domestic runoff (Conley et al. 2019; Corradini et al. 2019; Gündoğdu et al. 2018; He et al. 2019; Li et al. 2018a; Rochman 2018; Steinmetz et al. 2016). Microplastic is released from atmospheric deposition, land-based sources, fertilisers, artificial turf, road and air transportation, textiles, coastal and tourism activities, commercial fishing, marine vessels, aquaculture, and oil rigs (Belzagui et al. 2019; Gieré et al. 2018; Kole et al. 2017; Liu et al. 2019b; Li et al. 2018a; Weithmann et al. 2018). Subsequently, microplastic accumulates in the deep sea, pristine polar regions, ice sheet, living organisms, and contaminants such as polycyclic aromatic hydrocarbons (PAH), heavy metals, and antibiotics (Obbard 2018; Woodall et al. 2014; Yu et al. 2018). Microplastic waste is further fragmentised into nanoplastic and then accumulatively ingested by living organisms, affecting their feeding, digestion, excretion, and reproduction processes.

To curb microplastic pollution, it is important to reach an understanding of not only the source of microplastic but also its transportation, degradation, and the possible solutions of microplastic pollution. The complex transportation and distribution processes of microplastic include the ocean dynamics (i.e. surface drifting, vertical mixing, beaching, settling, and entrainment) and the physical characteristics of microplastic (i.e. size, shape, and density) (Enders et al. 2015; Guo et al. 2020; Kanhai et al. 2018; Li et al. 2020; Woodall et al. 2014). Ocean dynamics have also caused large areas of surface convergence, naturally accumulating up to 580,000 plastic pieces per square kilometre, such as the garbage patches near the Kuroshio Extension and in the western North Atlantic Ocean and Caribbean Sea (Howell et al. 2012; Law et al. 2010; Maximenko et al. 2012; Yamashita and Tanimura 2007). Organic aggregates or microorganisms, such as diatoms, can rapidly accumulate on the surface of plastic debris and form a biofilm, which then increases the density and causes the sinking of the floating or suspended low-density microplastic, hence redistributing the latter (Galgani et al. 2015; Zhang 2017; Zhao et al. 2018; Zhao et al. 2017).

Furthermore, marine microplastic can be ingested and introduced to the biological systems of a wide range of organisms from herbivores and secondary consumers to the predators of higher trophic levels, such as microorganisms, planktons, benthic invertebrates, (Naidu et al. 2018), fish (Savoca et al. 2019), deep ocean biota (Courtene-Jones et al. 2017), and larger mammals (Barboza et al. 2018a; Besseling et al. 2015; Wang et al. 2020b), causing neurotoxicity and genotoxicity, as well as reduced feeding, filtration, survival, and reproductive abilities (Zhang et al. 2019a). These effects decrease the quantity and quality of the food supply to humans and other aquatic organisms (Wong et al. 2020). Moreover, microorganisms including pathogens were discovered to be associated with microplastic (Brandon et al. 2018; Syranidou et al. 2017). Among the bacteria groups detected in microplastic were Bacillus sp. Paenibacillus sp., Actinobacteria, and Firmicutes (Lwanga et al. 2018; Park and Kim 2019). Although microplastic can persist in the environment and resist degradation, some microplasticassociated bacteria can degrade microplastic (Alimi et al. 2018; Kim et al. 2017b; Sen and Raut 2015; Yuan et al. 2020). Different bacteria consortia have different microplastic degradation abilities depending on the types of bacteria and enzymes (Tsiota et al. 2018). Reports have also shown that bacteria not exclusively associated with plastic have been colonising microplastic, which included the families of Rhodobacteraceae, Hyphomonadaceae, and Sphingomonadaceae (Mata et al. 2017; Moura et al. 2018; Oberbeckmann et al. 2018).

The use of microplastic-degrading microbes can enhance the biodegradation of marine microplastic already subjected to weathering and external physicochemical factors (Oberbeckmann and Labrenz 2020; Qi et al. 2017). Although microplastic is difficult to biodegrade, it offers support for microbial colonisation and growth (Rujnic-Sokele and Pilipovic 2017). Pores and irregularities that were observed on the surface of microplastic, such as polypropylene (PP), polyethylene (PE), polyethylene terephthalate (PET), polystyrene (PS), and polylactic acid (PLA), showed adhesion, colonisation, and damage by the associated bacterial and fungal strains, for example Aspergillus flavus (Auta et al. 2018; Kim et al. 2017a; Mohan et al. 2016; Paco et al. 2017; Devi et al. 2015; Uscategui et al. 2016; Yoshida et al. 2016). Additionally, worms have been reported to degrade plastics (Yang et al. 2015b). Although microplastic can be biodegraded gradually, ageing primary or secondary 
microplastic is constantly structurally altered or fragmented through biological, mechanical, or chemical degradation in the environment into nanoplastic, which further increases its bioavailability to living organisms (Hernandez et al. 2017; Liu et al. 2019a; Wang et al. 2019a). Furthermore, microplastic is a vector of harmful pollutants such as persistent organic pollutants (POP) and heavy metals, capable of transporting contaminants to the ecosystem via the food chain (Kwon et al. 2017; Wang et al. 2020a; Zhang et al. 2020a). Microplastic can hence increase the bioavailability of pollutants to ecosystems and organisms through sorption and bioaccumulation (Guzzetti et al. 2018; Horton et al. 2017).

The strategies and solutions to mitigate microplastic pollution include source control, remediation, clean up, regional involvement, and research (Agamuthu et al. 2019; Ma et al. 2020b; Wu et al. 2017). For example, the European Union has banned primary microplastic and disposable plastics and encourages the controlled release of marine litter. The United Nations has proposed individual measures that can help to lighten microplastic pollution, such as recycling and consumption control (Barceló and Picó 2020). Non-governmental organisations and international and national authorities, such as Surfider Foundation Europe and United Nations Environment Program Mediterranean Action Plan, were also involved in the practice or implementation of circular economy systems, and coastal and marine debris management (Agamuthu et al. 2019; Camins et al. 2020). Other efforts to alleviate microplastic pollution also include research on the application of water treatment systems and microbial degradation or biosynthesis of plastic-like material (Amelia et al. 2019; Bolto and Xie 2019; Hu et al. 2019; Ngo et al. 2019; Raju et al. 2018; Sun et al. 2019; Talvitie et al. 2017; Zhang et al. 2020a; Zhang and Chen 2020). Additionally, the fundamental research on plastic cannot be ignored as an in-depth understanding of microplastic characterisation based on its polymer type and morphology is needed to identify the most to the least environmentally harmful types of microplastic.

Overall, systematic management of and innovative research on reducing plastic waste materials at the source, removing microplastic in wastewater treatment facilities or increasing the use of bioplastic or easily biodegradable plastic, is needed to solve the issue of microplastic contamination. However, the understanding of the severity and impact of microplastic is important to mitigate microplastic pollution. With the increasing quantity of literature concerning the abundance and ubiquitous distribution of microplastic globally, research attention has been shifted toward the direct and indirect consequences of microplastic. Therefore, this review mainly focused on the possible factors that influenced pollutant sorption or bioaccumulation by microplastic, the health risks of microplastic to humans and other living organisms of the marine ecosystem, and the abundance and distribution of microplastic.

\section{Review}

2.1 Types, abundance, and distribution of microplastic Microplastic can be categorised on the basis of its original manufactured size, morphology, density, and material. Microplastic is defined as a plastic material with an average size of less than $5 \mathrm{~mm}$. The fragmentation of larger plastic in the environment is caused by chemical (e.g. photolysis, hydrolysis, and thermal), mechanical (e.g. abrasion), and biological (e.g. bacteria and fungi) degradation (Andrady 2011; Ivleva et al. 2017). The classification of microplastic is subjected to two categories, namely primary microplastic (i.e. microplastic produced in micro-sized particles such as microbeads) and secondary microplastic (i.e. microplastic from the breakdown of larger plastic materials) (Duis and Coors 2016). Primary microplastic is originally manufactured as microplastic that is usually applied in cosmeceutical products, drug vectors, and engineering or industrial applications (Auta et al. 2017). In contrast, secondary microplastic is originally manufactured as relatively large plastic that is degraded and fragmented into smaller pieces by complex weathering interactions (Rocha-Santos and Duarte 2015). Based on the morphotypes or types of morphologies, microplastic consists of fibres, fragments, films, pellets, beads, and Styrofoam. The abundance of microplastic in a water column depends on its density, wherein low-density microplastic such as PE and PP is buoyant in the water, while high-density microplastic tends to sink in the sediment (Sul and Costa 2014).

\subsection{Fibres}

Numerous research work has generally revealed that the heterogeneity of microplastic abundance has been mostly influenced by human activities such as wastewater discharge, industrial discharge, mariculture, and settlement. For example, research work in the Yangtze estuary and coastal area of the East China Sea revealed fibre as the dominant morphotype collected up to 79.1\% and $83.2 \%$, respectively (Zhao et al. 2014). The influx from the river to the sea is believed to play a significant role in introducing microplastic to the estuary and coastal areas. Anthropogenic activities such as landbased and fisheries activities trigger the abundance of microplastic.

For Xiangshan Bay, China, the source of microplastic pollution is dominated by the presence of mariculture activities. Chen et al. (2018) revealed more than $50 \%$ of microplastic of the fibre type derived from mariculture activities. Seawater samples were collected with plankton 
net tows involving nine sites. Microplastic derived from PE, PP, and PS was detected during the period of study. At another mariculture site in Maowei Sea, China, a similar pattern of a majority of fibre made from the PET, PP, and PE polymers was observed (Zhu et al. 2019). The riverine influx nearby thus enhanced the abundance of microplastic in the Maowei Sea.

A comprehensive study was carried out by Dai et al. (2018) to understand the impact of human intervention on microplastic pollution in Bohai Sea waters. In all, $75 \%$ of the microplastic collected by the researchers fell under the morphotype of fibre. The fraction of fibres in the surface layer was lower than that in the deeper levels of the water column. Sample collection using a stainlesssteel bucket was believed to have easily trapped fibre as compared to other methods such as those using mantra nets or neustonic trawls. In the surface water of the North Yellow Sea, film and fibre were the dominant morphotypes reported by Zhu et al. (2018b). Microplastic abundance was high with an average value of $545 \pm$ 282 items $/ \mathrm{m}^{3}$. PE was identified as a major contributor of microplastic composition in surface water. The Chinese coastal current and the Korean coastal current were speculated to introduce floating microplastic into the North Yellow Sea. Domestic sewage and fishing activities were the main sources of plastic pollution in this area.

Microplastic abundance and distribution research has been focused on regions that are highly influenced by human activities, such as the closed ecosystem of Jiaozhou Bay, China. The morphotype of black or blue fibre is the main characteristic of microplastic found in the collected samples. Polyamide (PA), polyvinyl acetate (PVA), PP, PE, and PET were the main groups of polymers found in this work. The Haibo river estuary was discovered to have strong riverine input to enhance microplastic flux into the bay. In addition, residual current and sediment mobility were other factors with a significant impact on the microplastic distribution and composition (Zheng et al. 2019).

Microplastic pollution was also observed in the west region of Asia. For example, a low abundance of microplastic was recorded in Qatar marine waters with an average concentration of 0.71 particle $/ \mathrm{m}^{3}$. The morphotypes of fibre and granule were spotted as the dominant types in the study (Castillo et al. 2016). The source of pollution was speculated to be derived from human anthropogenic activities, including oil-rig installation and ship operations. In the Arabic region, Aliabad et al. (2019) conducted a study on the microplastic abundance in Chabahar Bay, Oman, involving surface water from the seven selected stations. The primary colours of the microplastics collected were white, blue, and red. A low concentration of microplastic abundance was recorded in this area with fibre as the dominant morphotype, made up of secondary microplastic. More than $60 \%$ of the analysed samples were detected to be PE and PP.

In the region of the Mediterranean Sea, the first study on microplastic abundance was reported by Kazour et al. (2019), which focused on a Lebanese coastal area, namely the Levantine Basin. This area was recognised as a polluted area with a high abundance of microplastic. More than $50 \%$ of the microplastics detected in the water samples were fibres, and PE was the most abundant material. On the other side of the Mediterranean Sea, Akarsu et al. (2020) explicated the abundance of microplastic in Mersin Bay, Turkey. The study area was reported to receive high discharge from wastewater treatment plants. Therefore, the fibre material type was expected to contribute a large portion of microplastic.

American and European continents also recorded varied microplastic abundance in the water column. For example, Sutton et al. (2016) found the occurrence of microplastic in San Francisco Bay, CA, USA. Fibres were dominant in the sample containing wastewater discharge. Furthermore, average microplastic abundance (4.5 particles $/ \mathrm{m}^{3}$ ) was found in Tampa Bay, Florida, in the water and sediment samples. In all, $88 \%$ of the microplastic detected in the water samples was fibres, followed by fragments and flakes (McEachern et al. 2019). The source of microplastic introduced into the aquatic ecosystem was believed to be wastewater treatment discharge. High microplastic abundance was found in the vicinity of the industrial area.

Studies on microplastic abundance in Swedish marine waters included Skagerrak/Kattegat, the Baltic Sea, and Gulf of Bothnia. Two different approaches, namely manta trawl and in situ pump filtering, were used to collect the microplastic from the seawater. The pump filtering method detected a higher microplastic concentration, 0.10 particles $/ \mathrm{m}^{3}$, than the manta trawl method, 0.04 particles $/ \mathrm{m}^{3}$. Fibre was the most frequently found morphotype in the water samples consisting of PE and PP (Schönlau et al. 2020). This study only took into account fibres longer than $1 \mathrm{~mm}$, and the transparent ones were excluded. Most of the synthetic fibres found in all the samples were black or blue, which might suggest ropes as a possible source of these fibres, as these colours are very popular for ropes and fishing gear in the studied area.

Microplastic was also detected in South Africa marine waters. Nel and Froneman (2015) reported a quantitative microplastic concentration in the water column ranging from 257 to 1215 particles $/ \mathrm{m}^{3}$ and the dominant proportion of the morphotype of fibre. The main source was believed to be land-based sewage effluent. Overall, the microplastic typically found to pollute the environment was generally of the morphotype of fibre or fragment (Fig. 1), PE, or PP material, and contributed by 


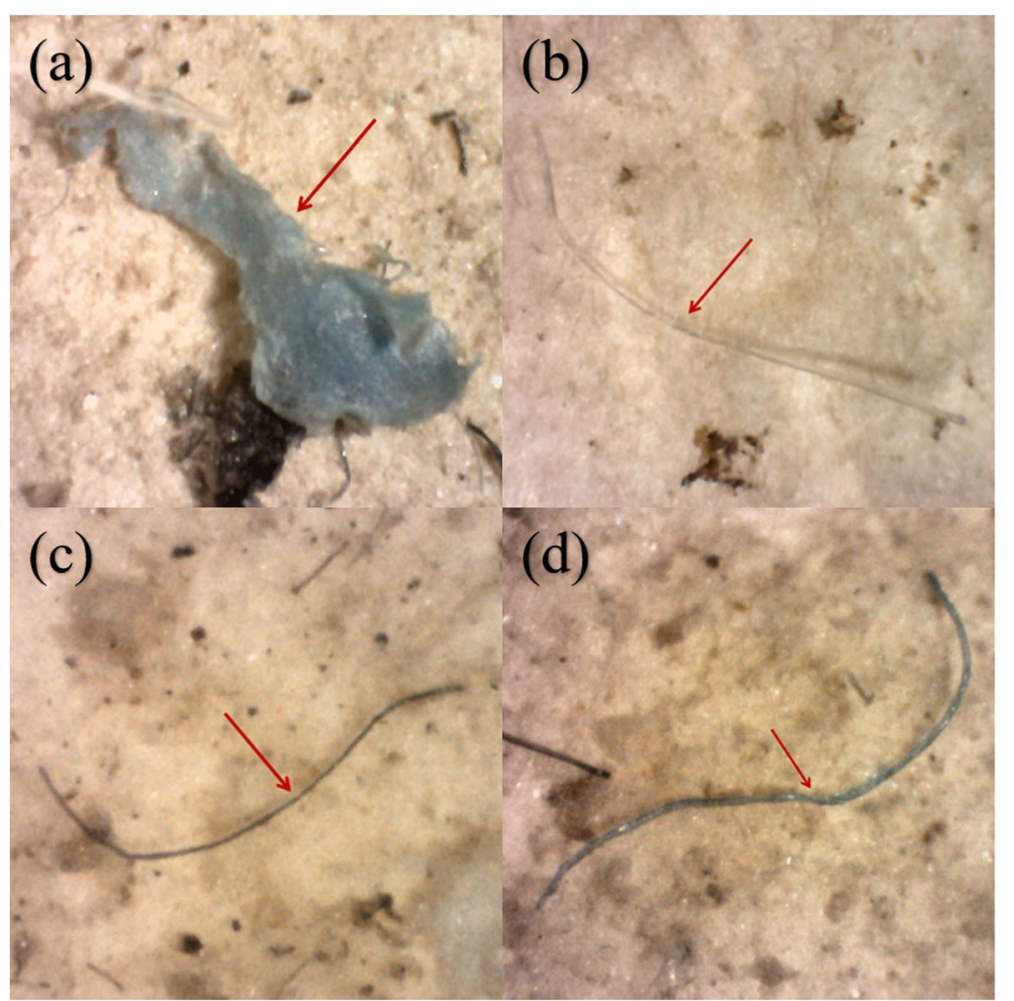

Fig. 1 Examples of microplastic morphotypes found in water samples. a Blue fragment, $\mathbf{b}$ transparent fibre, $\mathbf{c}$ black fibre, and $\mathbf{d}$ blue fibre

anthropogenic, urban, fishery, or marine activities. The dominant colours were blue and black. Fibres were either tangled or untangled, as well as straight or curved.

In the Oceania region, low microplastic abundance in the water, sediment, and fish samples was recorded in the coastal area of Suva, Republic of Fiji (Ferreira et al. 2020). The microplastic in the seawater samples was obtained using planktonic circular tows. The microplastic in the water samples of Laucala Bay, Suva Harbour, and vanua Navakavu was less than $0.24 \mathrm{item} / \mathrm{m}^{3}$. MPs were categorised as fibres $(60.2 \% \pm 6.9 \%)$ and fragments $(26.9 \% \pm 3.5 \%)$, whereas the lowest percentage was found to be films $(9.4 \% \pm 2.0 \%)$ and microbeads $(3.5 \% \pm$ $1.7 \%)$. The microplastic material analysis revealed 15 polymer types, with PE, PP, latex, and nylon as the major contributors. Interestingly, the source appointment of microplastic pollution was believed to be derived from anthropogenic activities despite the marine protected area, vanua Navakavu, being the most affected area.

\subsection{Fragments}

An analysis of Bohai Sea waters revealed that lowdensity polymers, such as PP, PE, and PS, were commonly found from all the 11 stations, where manta net was towed horizontally at the surface for $15 \mathrm{~min}$ at approximately 1.5 to 2.0 knots for each transect (Table 1 ). The most abundant morphotype was fragment in this work, which accounted for $46 \%$ of the total plastic collected. The source of microplastic was linked to fishing activities and marine farming in the Bohai Sea (Zhang et al. 2017).

The first observation in the Yellow Sea revealed a low abundance of microplastic dominated with the morphotype of fragment by $42 \%$. The main polymers identified using micro-Fourier-transform infrared spectroscopy (micro-FTIR) were PP and PE, accounting for 55.93\% and $32.20 \%$ of the total microplastic, respectively. High concentrations were observed close to coastal cities, thus indicating that the Yellow Sea coastal current played a significant role in the microplastic distribution (Sun et al. 2018).

The heterogeneity of microplastic was also found in Malaysian marine waters. Research work by Khalik et al. (2018) explicated two geological regions with different human activities, which exhibited a contradicting pattern of microplastic abundance. The first region located in Kuantan, Malaysia, is a port, while the second location situated in Kuala Nerus, Terengganu, is a non-urban area. Kuala Nerus focused on commercial fishing and tourism, while Kuantan port is one of the major multicargo ports in Malaysia. Kuala Nerus had higher microplastic abundance, 0.13-0.69 pieces/L, than Kuantan port with $0.14-0.15$ pieces/L. The uniform microplastic abundance was believed to be caused by a closed system, 
Table 1 Heterogeneity of MPs abundances in different region worldwide

\begin{tabular}{|c|c|c|c|c|}
\hline Region & Location & MPs concentration range & Polymer & Reference \\
\hline \multirow[t]{12}{*}{ Asian } & Yangtze Estuary, China & $500-10,200 \mathrm{n} / \mathrm{m}^{3}$ & Not Available & Zhao et al. (2014) \\
\hline & Yellow Sea, China & $\mathrm{ND}-0.81 \mathrm{item} / \mathrm{m}^{3}$ & $P P, P E$ & Sun et al. (2018) \\
\hline & Jiaozhou Bay, China & $20-120$ item $/ \mathrm{m}^{3}$ & $P P, P E, P E T$ & Zheng et al. (2019) \\
\hline & Bohai Sea, China & $0.01-1.5$ particle $/ \mathrm{m}^{3}$ & PE, PP, PS, PET & Zhang et al. (2017) \\
\hline & Xiangshan Bay, China & 4.6-20.1 item $/ \mathrm{m}^{3}$ & $P E, P P, P S$ & Chen et al. (2018) \\
\hline & Qatar marine waters & $0-3$ item $/ \mathrm{m}^{3}$ & $P E, P P, P S, P A, P M M A$ & Castillo et al. (2016) \\
\hline & Chabahar Bay, Oman & $0.07-1.14$ particle $/ \mathrm{m}^{3}$ & $P E, P P, P S, P E T, P V A$ & Aliabad et al. (2019) \\
\hline & Levantine Basin, Lebanon & $0.17-0.62$ item $/ \mathrm{m}^{3}$ & PE, PP, PS, PA, PET, PUR, PVC & Kazour et al. (2019) \\
\hline & Mersin Bay, Turkey & $0.2-5.1 \mathrm{pcs} / \mathrm{L}$ & $P E, P P, P S$ & Akarsu et al. (2020) \\
\hline & North Coast of Surabaya, Indonesia & $0.38-0.61 \mathrm{~N} / \mathrm{L}$ & $P S, P E, P P, P U, P E T, P B, P E S$ & Cordova et al. (2019) \\
\hline & Kuala Nerus and Kuantan Port, Malaysia & $0.13-0.69 \mathrm{pcs} / \mathrm{L}$ & PES, PE, PP, PS, PA, PVC & Khalik et al. (2018) \\
\hline & Southern Sri Lanka & $0-29$ item $/ \mathrm{m}^{3}$ & $P E, P P, P S$ and Mix PE+PP & Koongolla et al. (2018) \\
\hline \multirow[t]{2}{*}{ America } & San Francisco Bay, USA & $15,000-2,000,000$ particle/km² & Not available & Sutton et al. (2016) \\
\hline & Tampa Bay, USA & 1.2-18.1 particles $/ \mathrm{m}^{3}$ & Not available & McEachern et al. (2019) \\
\hline \multirow[t]{2}{*}{ Europe } & Sweden marine waters & $0-70.3$ item $/ \mathrm{m}^{3}$ & $P E, P P$ & Schönlau et al. (2020) \\
\hline & Tuscan coastal waters, Italy & $0.16-0.27$ item $/ \mathrm{m}^{3}$ & $P E, P P, E V A, S B R$ & Baini et al. (2018) \\
\hline \multirow[t]{2}{*}{ Africa } & King Harbour, Jamaica & 0-5.73 particle $/ \mathrm{m}^{3}$ & $P E, P P$ & Rose and Webber (2019) \\
\hline & South Africa marine waters & 257-1215 particle/m³ & Not available & Nel and Froneman (2015) \\
\hline
\end{tabular}

such as a port, that limited the intrusion of plastic pollutants from the open sea. Six polymers were identified from both the locations, namely PET, PS, PA, PVC, PP, and PE.

Saliu et al. (2018) proved the occurrence of microplastic in Faafu Atoll, Maldives. Surface seawater was taken using neuston net involving 12 locations. This area had low population density and influx from tourism activities. However, the average microplastic abundance in Faafu Atoll waters was $0.32 \pm 0.15$ particles $/ \mathrm{m}^{3}$. Microplastics of the fragment morphotype found in a high fraction contributed up to $52 \%$ of the total particles in the analyses.

In addition, Savoca et al. (2019) discussed the occurrence of microplastic in Tyrrhenian waters, the Mediterranean Sea. Water samples were taken using a Bongo net with a diameter of $60 \mathrm{~cm}$. The microplastic found in the seawater was dominated by the fragment type and originated from polyvinyl chloride (PVC) and lowdensity polyethylene (LDPE) materials. The blue colour of the plastic fragments was the most dominant colour, reaching 56.25\%. In South Asia, the abundance of microplastic varied between counties. A preliminary work carried out in Southern Sri Lanka by Koongolla et al. (2018) revealed that $70 \%$ of the collected water samples contained microplastic. The morphotype of fragment was dominant, and the microplastic composition was largely contributed by PE and PP. Countries with tourismdriven economies, such as the Maldives, also experienced microplastic pollution in the water column.
In Spanish marine waters, Ruiz-Orejón et al. (2018) reported the occurrence of microplastic in the coastal waters of the Balearic Islands. Water samples were taken using a mantra trawl net. More than $90 \%$ of the plastic materials collected were identified as the morphotype of fragment with a dominant size range of 0.5 to $1.3 \mathrm{~mm}$. Plastic with a micro size showed a stronger prevalence than that with the meso and macro sizes. A high density of microplastic was recorded in the water column, close to the coastal line, particularly in the first $10 \mathrm{~km}$. Italian marine waters also experienced microplastic pollution as reported by Baini et al. (2018) in the Tuscan coastal waters. Surface samples were collected using a manta trawl, involving four transects located along the Tuscan coast. The average microplastic abundance was low, 0.26 item/ $\mathrm{m}^{3}$, with PE and PP identified as the main source of microplastic in this area. Fragments were the most prevalent type $(62 \%)$ found in the water samples, followed by filaments (29\%); the highest abundance was of particles of the size of $<1 \mathrm{~mm}(52 \%)$.

For the African region, microplastic abundance was also reported at different locations. For example, microplastic abundance was studied in King Harbour, Jamaica. Samples were taken using a mantra trawl net. The microplastic concentrations varied from 0 to 5.73 particles $/ \mathrm{m}^{3}$. The morphotype of fragment was the most frequently found from the collected samples with sizes ranging from 1 to $2.5 \mathrm{~mm}$. Microplastics have also been characterised by a wide variety of colours, most of which are transparent, accounting for $35 \%$. The FTIR analysis 
indicated the PE and PP composition for the morphotype of fragment (Rose and Webber 2019).

Saeed et al. (2020) conducted the first survey to understand the occurrence of microplastic in Kuwait marine waters. Their findings revealed lower microplastic abundance in the water samples than the other matrices such as sediment and fish. Neuston nets were used to trap the microplastics from the seawater samples. In all, 37 microplastics were found in only 15 stations out of the 44 sampling stations, where each trawl was approximately $1 \mathrm{~km}$. The PP and PE polymers were identified using Raman spectroscopy. Six of the microplastics were described as the fragment morphotype, while the remaining were labelled as the filament morphotype.

\subsection{Other types}

In the South China Sea region, researchers reported microplastic abundance in the water samples of Nansha Island, China. The microplastic concentration analysed from 15 water samples was high at 1733 item $/ \mathrm{m}^{3}$. Microbead was reported to be the dominant morphotype and accounted for $76.5 \%$ of all the detected microplastic (Nie et al. 2019). However, in Hong Kong marine waters, Tsang et al. (2017) found a relatively low density of microplastic, such as PP and PE. The morphotype of pellet was identified as the main fraction of the microplastic, accounting for $96.8 \%$. Discharge from a nearby river, Pearl River or untreated sewage, storm runoff, and other land-based activities were believed to contribute as the sources of the plastic pollution.

In Southeast Asia, a similar trend was reported by many researchers, for example, the microplastic abundance in the north coast of Surabaya. Microplastic concentrations ranged from 0.38 to $0.61 \mathrm{item} / \mathrm{L}$, in three selected areas namely the Lamong Bay, Kenjeran Beach, and Wonorejo coastal area. A high contribution was derived from the close proximity to human settlements and shipping activities. The foam type was reported to be the dominant morphotype, which accounted for $58.4 \%$ of all the detected microplastic. Seven polymers were identified from the studied location, and polystyrene was the most frequently detected in the samples (Cordova et al. 2019).

\subsection{Pollutant sorption of microplastic and its factors}

With the global severity of microplastic pollution, at least 80 countries have publications about microplastic sorbing pollutants, among which the major countries are China, the USA, the UK, Italy, and South Korea (Yu et al. 2019a). Research on microplastic sorption has been increasing as microplastic is gaining attention as a vector or carrier of harmful contaminants, such as POP and heavy metals (Brennecke et al. 2016; Kwon et al. 2017).
Recently, in the field of microplastic, the terms 'absorb' and 'sorb' have been used in addition to the more commonly used 'adsorb' to distinctly mean adsorption, absorption, both adsorption and absorption, or either one of the former two situations (Huffer et al. 2018; Katsnelson 2015; Munier and Bendell 2018; Xia et al. 2020). According to Dictionary.com and Oxford University Press, 'sorb' is defined as 'to gather on a surface either by absorption, or adsorption, or a combination of the two processes' ('Sorb" 2020). The terms 'adsorb' and 'absorb' are defined as 'hold molecules as a thin film on the outside surface or on internal surfaces within the material' and 'take in or soak up substance by chemical or physical action', respectively ("Adsorb" 2020; "Absorb" 2020). In the recent publications in the microplastic field, 'adsorb' and 'absorb' are referred to as 'sorbed onto the surface of microplastic' and 'sorbed into the bulk phase of microplastic', respectively (Endo et al. 2008; Huffer et al. 2018; Katsnelson 2015). The distinction of surface adsorption and bulk absorption could shed new insights behind the mechanism of pollutant sorption by microplastics, the behaviour of microplastic-pollutant complexes, or the complete vector capacity of multiple microplastic types (Huffer et al. 2018; Katsnelson 2015). For example, certain substances such as minerals and rigid carbonaceous geosorbents (charcoal and soot) tend to adsorb compounds, whereas organic contaminants tend to absorb into organic matter (Endo et al. 2008).

Although the biological or mechanical degradation of microplastic can lead to its fragmentation, increased surface area, enhanced bioavailability, and subsequently, its sorption of pollutants, other chemical degradation and ultraviolet (UV) light can also change the functional groups and other chemical properties of microplastic, and hence, more directly aggravate the sorption of pollutants by microplastic (Göpferich 1995; Hernandez et al. 2017; Horton et al. 2016; Jun et al. 2014; Liu et al. 2019a; Ter et al. 2016; Wang et al. 2019a). Microplastic can sorb environmental contaminants that include hydrophobic organic pollutants (i.e. PAH, polychlorinated biphenyl $[\mathrm{PCB}])$, hydrophilic organic pollutants (i.e. perfluoroalkyl acids [PFAA]), drugs, and metals (Table 2). The factors known to affect the pollutant sorption capacity of microplastic are the colour, density, age, and chemical properties of the microplastic, type of pollutant, biofilm presence, and environmental conditions such as dissolved organic matter, $\mathrm{pH}$, and salinity (Fisner et al. 2017; Frias et al. 2013; Fries and Zarfl 2012; Wang et al. 2015).

\subsection{Physical properties of microplastic as a factor}

The physical and chemical properties of microplastic have been proven to affect its pollutant sorption capacity (Fisner et al. 2017; Fries and Zarfl 2012; Huffer et al. 
Table 2 Types of pollutants carried by different types of microplastics

\begin{tabular}{|c|c|c|}
\hline Microplastic & Pollutant & Reference \\
\hline PA & Benzene derivative & Rehse et al. (2018) \\
\hline PBAT & Heavy metals & Kedzierski et al. (2018) \\
\hline \multirow[t]{9}{*}{ PE } & Lubrication oil & Haghi and Banaee (2017) \\
\hline & PAH & Oliveira et al. (2013) \\
\hline & Paraquat & Rochman et al. (2013b) \\
\hline & PBDE & Llorca et al. (2018) \\
\hline & PCB & Wang et al. (2015) \\
\hline & Per- and polyfluoroalkyl substances & Fisner et al. (2017) \\
\hline & PFOSA & Zhan et al. (2016) \\
\hline & PPCP & Hu et al. (2017) \\
\hline & Triclosan & Frydkjær et al. (2017) \\
\hline PET & Heavy metals & Rochman et al. (2013a) \\
\hline \multirow[t]{2}{*}{ PP } & Heavy metals & Rochman et al. (2013b) \\
\hline & $\mathrm{PAH}$ & Fisner et al. (2017) \\
\hline \multirow[t]{7}{*}{ PS } & Antibiotic & Wen et al. (2018) \\
\hline & Cadmium & Zhang et al. (2019b) \\
\hline & Lubrication oil & Llorca et al. (2018) \\
\hline & PCB & Wang et al. (2015) \\
\hline & Per- and polyfluoroalkyl substances & Guo et al. (2018) \\
\hline & PFOSA & Zhan et al. (2016) \\
\hline & Roxithromycin & Hu et al. (2017) \\
\hline \multirow[t]{9}{*}{ PVC } & 17a-Ethinylestradiol & Qu et al. (2018) \\
\hline & Antibiotic & Sleight et al. (2017) \\
\hline & Benzene derivatives & Kedzierski et al. (2018) \\
\hline & Heavy metals & Rochman et al. (2013a) \\
\hline & Odesmethylvelafaxine & Pascall et al. (2005) \\
\hline & PCB & Wu et al. (2016) \\
\hline & PFOSA & Guo et al. (2018) \\
\hline & Phenanthrene & \\
\hline & Venlafaxine & \\
\hline LDPE & Heavy metals & Rochman et al. (2013a) \\
\hline HDPE & Heavy metals & Holmes et al. (2014) \\
\hline
\end{tabular}

PBAT polybutylene adipate terephthalate, HDPE high-density polyethylene, PFOSA perfluorooctanesulfonamide, $P P C P$ pharmaceuticals personal care product

2018; Llorca et al. 2018; Ma et al. 2020a). It has been reported that the microplastic of a lighter colour contained PAH of lower molecular weight and lower concentrations of PAH or PCB than the microplastic of a darker colour (Antunes et al. 2013; Fisner et al. 2017). The hypothesised relationship between colour and chemical composition against microplastic sorption can encourage research for alternative colour pigments that are environmentally friendly (Ma et al. 2020a). Furthermore, microplastics of higher density were reported to contain lower concentrations of $\mathrm{PAH}, \mathrm{PCB}$, and phenanthrene (Fries and Zarfl 2012; Karapanagioti and Klontza 2008; Mato et al. 2001).
The ageing of microplastic cannot be ignored because weathered microplastic not only increases in surface area but also generates oxygen groups, porosity, roughness, charge, and polarity (Fotopoulou and Karapanagioti 2012). Hydrogen bonds formed among the oxygencontaining functional groups of aged microplastic can substantially increase the sorption capacity (Huffer et al. 2018; Liu et al. 2018). In an experiment by Kedzierski et al. with 502 day long-term exposure, $\mathrm{Ni}$ and $\mathrm{Cu}$ were found on PVC. Si, $\mathrm{Al}, \mathrm{Fe}$, and $\mathrm{Mg}$ were found on polybutylene adipate terephthalate (PBAT) after 1 year, while no change was observed for PET over the entire period (Kedzierski et al. 2018). Moreover, the effect of 
microplastic ageing on pollutant sorption capacity varies in the past reports. According to $\mathrm{Ma}$ et al. weathered or aged microplastic was reported to possess less pollutant sorption capacity (Ma et al. 2020a). However, aged microplastic was also reported to show higher pollutant sorption capacity than virgin microplastic (Huffer et al. 2018; Liu et al. 2018; Yu et al. 2019a). The colour, density, and surface morphology or weathering or microplastic play a role synergistically at influencing the sorption ability of a microplastic particle, and the sequence of factors mentioned does not reflect the importance of a factor over the other. Mixed findings from the past literature suggest that the effect of microplastic ageing on pollutant sorption capacity depends on the type of pollutant or microplastic, and the gradual changes in their chemical bonds, forces, or interactions over time.

\subsection{Chemical properties of microplastic as a factor}

Besides physical properties, the chemical properties of microplastic and pollutants, such as composition, synthesis method, crystallinity, stability, polarity, functional group, and chemical bonding, also influence the sorption capacity of microplastic ( $\mathrm{Li}$ et al. 2018b; Llorca et al. 2018; Wang et al. 2015). A chemical structure with a large surface area or porosity can lead to higher sorption capacity. For example, the sorption capacity of PE was the highest, but the sorption rate of PET was the highest. The former's larger surface area, greater gap between polymer chains, and free volume led to relatively higher sorption capacity and diffusion of the pollutant into PE (Karapanagioti and Klontza 2008; Rochman et al. 2013a; Teuten et al. 2007). In contrast, the faster sorption rate on PET could be attributed to its smaller surface area and glassy polymeric structure, which does not facilitate diffusion into the material as compared to PE that absorbs more pollutants into structural gaps within the polymer (Pascall et al. 2005; Teuten et al. 2007).

The affinity of pollutants with microplastic varies as it depends on chemical interactions, including electrostatic interaction, van der Waals force, hydrophobic interaction, $\pi-\pi$ interaction, or hydrogen bonding (Ma et al. 2020a) (Fig. 2). For example, the hydrogen bonding between PA and antibiotics caused strong affinity because of the amide groups ( $\mathrm{Li}$ et al. 2018b). In another example, between carboxyl-functionalised polystyrene (PS-COOH) and amine-modified polystyrene $\left(\mathrm{PS}-\mathrm{NH}_{2}\right)$ with different surface charges, the latter caused embryonic apoptosis, cell death, oxidative stress, and cell membrane disruption on the embryos of sea urchin Paracentrotus lividus (Vega and Epel 2004).

Hydrophobic POP are currently among the most researched microplastic-associated pollutants because of their high affinity and hydrophobicity-driven sorption with microplastic (Liu et al. 2019d; Rios et al. 2007). Hydrophobic organic pollutants include $\mathrm{PCB}, \mathrm{PAH}$, and other endocrine-disrupting chemicals (EDC) or benzene derivatives (Ma et al. 2017; Ma et al. 2018; Velzeboer et al. 2014). For example, the strong interaction between microplastic and hydrophobic organic PAH in the aquatic environment has been reported ubiquitously (Tan et al. 2019). In terms of crystallinity, hydrophobic organic pollutants typically favoured amorphous to crystalline structures, as organic contaminants harboured higher affinities for rubber plastics than glass plastics (Guo et al. 2012; Rochman et al. 2013a; Wu et al. 2001).

Hydrophilic POP, represented by perfluorooctanesulfonate (PFOS) and perfluorooctanesulfonamide

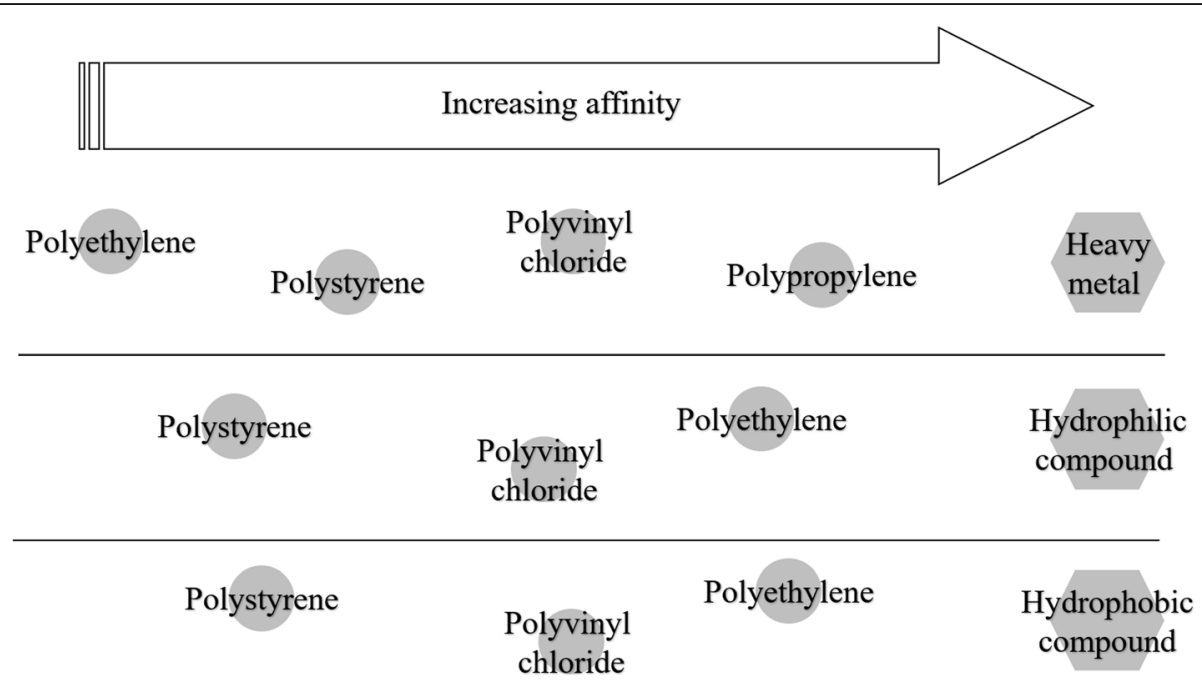

Fig. 2 A general illustration depicting the varied affinity of different microplastics to different environmental pollutants such as heavy metals, hydrophilic compounds, and hydrophobic compounds 
(PFOSA), interact dominantly with microplastic via partitioning rather than electrostatic force and hydrophobicity. The PFOS is mainly anionic, whereas PFOSA is non-ionic because of the sulphonamide functional group; PE is thus more attracted to PFOSA because of the presence of the functional group (Wang et al. 2015). Furthermore, PE, PS, PP, PA, and PVC microplastics were found to sorb hydrophilic antibiotics, such as trimethoprim (TMP), ciprofloxacin hydrochloride (CIP $\mathrm{HCl}$ ), tetracycline (TC), amoxicillin (AMX), and sulfadiazine (SDZ) (Li et al. 2018b; Shen et al. 2018).

Different types of microplastics possess varied pollutant sorption and affinity as their dissimilar structure generates different chemical interactions, such as hydrophobicity or hydrophilicity. For example, non-polar PFOSA was more attracted to the non-polar PE via hydrophobic interactions but less attracted to the benzene-containing PS caused by decreased free volume, steric hindrance, and bond rotation (Wang et al. 2015). However, Yu et al. reported that PS can generate planarity, hydrophobic, and $\pi-\pi$ interactions, whereas PE can generate only van der Waals interactions (Yu et al. 2019b). Contradictions were also reported regarding the type of plastic as a sorption factor, where no difference in PAH sorption was observed in PP and PE (Fisner et al. 2017). In-depth investigation is required to discover additional trends and associations of physical or chemical properties that are responsible for the sorption capacity of a microplastic with a specific pollutant.

Furthermore, a stronger hydrophobic interaction causes microplastic to attract benzene derivatives rather than single benzene (Huffer and Hofmann 2016). The PVC microplastic was reported to attract five bisphenol analogues by hydrophobic, $\pi-\pi$, covalent hydrogen, and halogen interactions. Electrostatic forces were present but are relatively easier to be influenced by external environmental factors (Wu et al. 2016). In contrast, PCB was reported to sorb more onto PE (highest uptake diffusion and partition coefficients) than PS and PVC. However, the sorption capacity with PVC reduced at higher chlorinated congeners because of the increasing cohesive density and molar volume of PCB (Pascall et al. 2005).

Additionally, the affinity or sorption capacity of microplastic and metals was neither temporally nor spatially associated (Yu et al. 2019b). High-density polyethylene (HDPE) was reported to have relatively lower affinity to metals than PET, PVC, LDPE, and PP (Rochman et al. 2013a). Sorption between metals and virgin or beached microplastic was rapid and significant. Virgin PE, which showed less affinity, possessed charged or polar surfaces, charged contaminants or additives, and nonspecific interactions between the metal organic complexes and the hydrophobic surface (Holmes et al. 2012). Beached or aged PE, which showed higher affinity to heavy metals, contained not only chemical precipitation and oxygencontaining groups but also biofilms, which may contribute to the relatively high partition coefficient (Brennecke et al. 2016; Mato et al. 2001; Turner and Holmes 2015). Overall, as the attraction of different pollutants to the respective plastics depends on the ever-changing environmental conditions and physicochemical properties of both the substances, the difficulty of selecting the 'best' type of plastic could likely encourage future research attention on the development of an inert material.

\subsection{Water properties as a factor}

Environmental conditions and water properties, such as dissolved organic matter, $\mathrm{pH}$, and salinity, have been reported to affect the pollutant sorption capacity of microplastic. The role of dissolved and particulate organic matter in microplastic sorption requires attention, as it can alter the in situ sorption capacity and distribution of marine microplastic (Besseling et al. 2016; Koelmans et al. 2009; Lambert et al. 2013). According to Wu et al. dissolved organic matter can influence the sorption process by (1) interacting with pollutants via complexation or hydrophobic interactions, (2) competition with other sorbents, and (3) subsequent interaction with pollutants after sorption onto other sorbents (Wu et al. 2016). The dissolved organic matter reduced the sorption capacity of PE for three pharmaceuticals and personal care products (PPCP), namely triclosan (TCS), $17 \alpha$-ethinyl estradiol (EE2), and 4-methylbenzylidene camphor $(4 \mathrm{MBC})$, because of the higher affinity between pharmaceuticals and dissolved organic matter. However, dissolved organic matter did not reduce the sorption of $\mathrm{PE}$ microplastic for carbamazepine (CBZ) (Wu et al. 2016).

Investigating the impact of $\mathrm{pH}$ on microplastic sorption is important, as the marine ecosystem has been experiencing acidification. As reported by Guo et al. the sorption capacity of PS and PVC for antibiotic tylosin (TYL) increases as $\mathrm{pH}$ decreases, because the proportion of $\mathrm{TYL}^{+}$is larger, while the sorption capacity of PP and PE has minimal changes (Guo et al. 2018). The sorption of PS and PE for PFOS also increases as pH decreases, which protonates the microplastic surface and produces more anionic PFOS. Additionally, the PE surface can be easier to protonate than the PS surface (Wang et al. 2015). However, when the $\mathrm{pH}$ decreases, the sorption capacity of HDPE for $\mathrm{Pb}, \mathrm{Ni}, \mathrm{Co}$, and $\mathrm{Cd}$ decreases, whereas for $\mathrm{Cr}$ and $\mathrm{Cu}$, the sorption capacity increases and remains constant, respectively (Holmes et al. 2012; Holmes et al. 2014). Overall, although the $\mathrm{pH}$ of the surrounding water has been shown to influence the pollutant sorption by microplastic, such as through protonation (Guo et al. 2018), the literature regarding 
the impact of $\mathrm{pH}$ against pollutant sorption by microplastic exhibits a need for a broader comparative or statistical approach to achieve insights into the associative patterns of $\mathrm{pH}$ with microplastic and pollutants.

Salinity has both positive and negative effects on the sorption behaviour. Increased salinity has been reported to increase sorption capacities (Velzeboer et al. 2014; Wang et al. 2015), such as elevated PCB or lubrication oil in PE and PS (Hu et al. 2017; Zhan et al. 2016). However, increased salinity was reported to decrease sorption capacities, namely in dichlorodiphenyltrichloroethane (DDT) and ciprofloxacin because of the competition for the sorption site (Bakir et al. 2014; Li et al. 2018b; Liu et al. 2018). Additionally, the effect of salinity was not obvious for phenanthrene (Bakir et al. 2014). Nonetheless, a fixed pattern was not present in terms of the salinity effect against metal sorption by microplastic. Increased salinity reduced the sorption capacity of $\mathrm{Cd}$, $\mathrm{Co}$, and $\mathrm{Ni}$ while increasing that of $\mathrm{Cr}$, but interestingly kept that of $\mathrm{Cu}$ and $\mathrm{Pb}$ constant. It is apparent from the literature that salinity influences sorption capacity by principally disturbing the free ions and the competition for sorption sites (Holmes et al. 2014).

In summary, the literature review suggested that chemical interactions could be a significant factor of pollutant sorption by microplastic, as the chemical bonds on a microplastic is not only associated with the physical properties of the polymer (i.e. material, colour, and age) but also the properties of the surrounding medium (i.e. $\mathrm{pH}$ and salinity). In other words, the underlying force that allows the other physical properties of the microplastic and the surrounding medium to affect its sorbability is the chemical bonding. For example, the influence of microplastic age and material against the sorption capacity of a pollutant was eventually still because of the differences in the surface functional groups, polarity, or chemical forces such as hydrophobicity over time or across various pollutant types (Huffer and Hofmann 2016; Liu et al. 2018). Research in the direction of investigating the chemical interactions between microplastic, pollutants, and the environment can disclose new indirect factors of pollutant sorption by microplastic.

\subsection{Hazards of microplastic to the marine ecosystem and its organisms}

The widely known impacts of large plastic debris are the loss of aesthetic impression, disrupted tourism- and marine-related economy (e.g. aquaculture, energy production, fishing, and shipping), and the death and injury of marine wildlife (Lusher et al. 2015). In contrast, although both macroplastic and microplastic can also transport pathogens and release plasticizers or additives, microplastic can sorb and desorb and, hence, bioaccumulate quantitatively more toxic pollutants because of the larger ratio of the surface area to the volume of the microplastic (Avio et al. 2017; Zettler et al. 2013; Teuten et al. 2009).

The existence of microplastic has been found in the guts of benthic invertebrates (Naidu et al. 2018; Nakki et al. 2017), fish (Savoca et al. 2019), deep ocean biota (Courtene-Jones et al. 2017), and larger mammals (Besseling et al. 2015) from different trophic levels. Ingested microplastic is transferred throughout the food web, driving increasing concerns about the threats to aquatic biota (Betts 2008; Wright et al. 2013a). Microplastic can accumulate and pose hazards in marine ecosystems and organisms (Guzzetti et al. 2018; Horton et al. 2017). Prior to understanding the threats of microplastic against marine organisms, it is imperative that we grasp the factors that affect the bioavailability of microplastic, as it indirectly affects the extent of dangers that the organisms are subjected to. The factors of microplastic bioavailability toward organisms are the size, colour, density, morphology, and mobility of microplastic, as well as the species, morphology, and physiology of organisms (e.g. ingestion likelihood, egestion rate, and translocation potential) (Baldwin 1995; Boerger et al. 2010; Cheung et al. 2018; Kokalj et al. 2018; Ory et al. 2017; Peters et al. 2017). Additionally, as each type of organism consumes microplastic differently because of the respective organism physiology and morphology, the representative model organisms selected in microplastic toxicological studies should be specifically based on the research objectives (Ma et al. 2020a). Nonetheless, the existing research has accumulatively confirmed that the types of organisms and the physicochemical traits of microplastic influence the bioavailability of microplastic to organisms, by altering the distribution and availability of microplastic as food for organisms, which influences the microplastic-associated hazards or extent of damage faced by different species (Setala et al. 2016).

Microplastic causes dangers to marine ecosystems and organisms through several approaches. In a typical marine ecosystem, microplastic acts as a reservoir or vector, thus accumulating chemical contaminants, transporting them over long distances, and leading to the high bioavailability of pollutants toward organisms when consumed (Avio et al. 2017; Brennecke et al. 2016; Caruso 2019; Liao and Yang 2020) (Fig. 3). Microplastic by itself without pollutants also poses various indirect and direct hazards to diverse organisms, which include translocation, physiological stress, energy budget alteration, abnormal metabolism, immune response, behavioural alteration, fecundity, egestion inefficiency, severe intestinal damage, and mortality (Besseling et al. 2015; Betts 2008; Courtene-Jones et al. 2017; Gambardella et al. 2017; Greven et al. 2016; Jeong et al. 2016; Jovanovic 


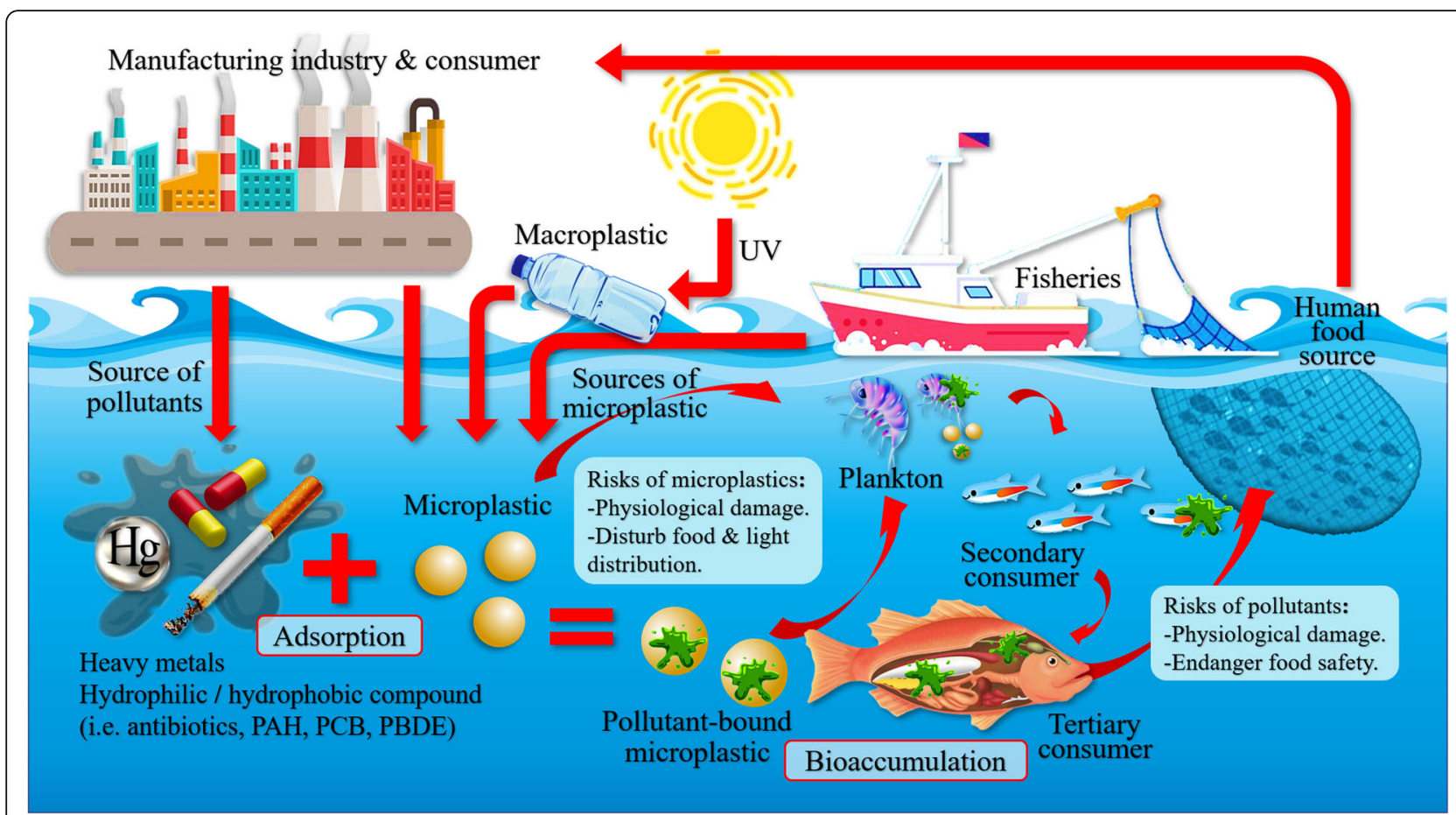

Fig. 3 An illustration of the pathways of microplastic and its general impact to the marine ecosystem and organisms

2017; Lei et al. 2018; Leroueil et al. 2008; Naidu et al. 2018; Nakki et al. 2017; Prokic et al. 2019; Savoca et al. 2019; Setala et al. 2014; Song et al. 2014; Vajargah et al. 2018; Vajargah et al. 2019; Veneman et al. 2017; Wright et al. 2013b). Other than having physiological effects, microplastic causes external effects to the ecosystem by shifting the distribution of food and light for organisms (Cole et al. 2016; Song et al. 2014).

The translocation of microplastic in marine organisms has been reported (Scanes et al. 2019; Windsor et al. 2019). The movement of microplastic through biological membranes can have varying impacts depending on the species and location that the microplastic is translocated to. The translocation routes can begin from the ingestion or inhalation of microplastic to the gastrointestinal tracts, gills, or lungs, and then to the circulatory system, haemolymph, liver, or kidney (Abbasi et al. 2018; Leroueil et al. 2008; Su et al. 2018; Vajargah et al. 2018; Vajargah et al. 2019). Moreover, microplastic causes gastrointestinal blockage, reduced feeding or satiation (Lusher et al. 2013), structural deterioration, nutritional or growth complications (Jabeen et al. 2018; Peda et al. 2016; Yin et al. 2018), inflammation (Lu et al. 2016), and alteration of metabolic profile (Mattsson et al. 2014).

Furthermore, microplastic contributed to egestion inefficiency and intestinal damage. For example, microplastic produced higher retention times in the monogonont rotifer, Brachionus koreanus (Jeong et al. 2016). In another example, microplastic in
Caenorhabditis elegans caused mortality, accumulation, lowered intestinal $\mathrm{Ca}^{2+}$ level, and elevated glutathione $\mathrm{S}$ transferase expression, which led to chronic intestinal damage (Lei et al. 2018). Additionally, microplastic was reported to externally affect marine organisms and ecosystems. A water surface that is polluted with microplastic impedes the respiration and photosynthesis of marine plankton (Amin et al. 2020; Song et al. 2014). Other than this, ingested microplastic that is excreted along with faecal matter can alter the density and sinking velocity of the latter, which is an important food source, hence interrupting the normal pattern of food distribution for other marine organisms (Cole et al. 2011, 2016).

However, contradictions were also reported. For example, limited acute toxicity and no mortality were observed from the ingestion of microplastic by the Antarctic krill Euphausia superba (Dawson et al. 2018). In summary, the sorption, aggregation, ingestion, retention, egestion, reingestion, and release of chemicals present potential mechanisms for the transport of POP and metals. The transfer and bioaccumulation of organic pollutants, such as $\mathrm{PAH}, \mathrm{PCB}, \mathrm{EDC}$, and polybrominated diphenyl ether (PBDE), in living organisms, such as lugworms, marine amphipods, mussels, rainbow fish, and microalgae, via sorption on microplastic have been detected (Fisner et al. 2017; Guo et al. 2020; Llorca et al. 2018; Rehse et al. 2018; Rochman et al. 2013b; Wang et al. 2020b). Although some studies have not reported significant negative effects of microplastic, reports on 
the hazards of microplastic toward the environment should not be ignored.

\subsection{Types of microplastic-bound pollutants bioaccumulated in organisms}

Microplastic pollution in the ocean is one of the most serious recent environmental problems. The ingestion of microplastic has been reported for a wide range of organisms, from herbivores and secondary consumers to the top predators (e.g. Barboza et al. 2018a; Clark et al. 2016; Nelms et al. 2018; Vroom et al. 2017; Wang et al. 2020b). Previous research has indicated the potential adverse and long-term environmental impacts of microplastic in the ocean. For example, the ingestion of larger microscopic particles may cause harmful physical effects to living organisms (Wright et al. 2013b). Moreover, other hypotheses suggested the deleterious effects of microplastic, regarding its role in the delivery of harmful chemicals to the ecosystem via the food chain (Avio et al. 2017; Hartmann et al. 2017; Lohmann 2017; Wang et al. 2018a; Wang et al. 2020b; Zhang et al. 2020a). It is well known that microplastic in seawater may sorb chemical pollutants, e.g. hydrophobic organic chemicals. These chemicals may originate from the chemical additives that were incorporated into plastics during manufacture (Kwon et al. 2017) or accumulated from the surrounding polluted water because of its high sorption capacity (Bakir et al. 2012; Liu et al. 2016; Velzeboer et al. 2014).

Similarly, when conditions move in the opposite direction that discourages sorption, contaminants are at risk of being desorbed from the ingested microplastic into the biological systems of living organisms. This situation makes microplastic both a source and a sink of pollutants (Liu et al. 2019c). Additionally, the reports of the bioaccumulation of toxic pollutants in other living organisms suggest a similar situation for humans, whereby microplastic-pollutant complexes can release the pollutants into the surrounding biological tissue. Therefore, this raises an important question of whether microplastic significantly contributes to the uptake and accumulation of environmental pollutants through the marine food web than the other sources.

Thus far, several types of environmental pollutants that can be found in living organisms along with plastic debris have been documented, which suggests that microplastic can act as vectors for the transfer of chemical contaminants from seawater to organisms (Table 3). Because of the hydrophobic surface of the plastics, a hydrophobic organic compound is the most noticeable category that transfers via this pathway. Plastic materials, such as PS, PE, and PP, may sorb hydrophobic organic compounds, namely $\mathrm{PCB}, \mathrm{PBDE}, \mathrm{PAH}$, and hexabromocyclododecane (HBCD), and then, carry them to organisms. Furthermore, recent studies have shown that microplastic can be a vector for heavy metal contamination in the marine environment (Brennecke et al. 2016; Davarpanah and Guilhermino 2015). The model animal, zebrafish (Danio rerio), exposed to Ag-incubated PE microbeads significantly increased the proportion of intestinal Ag levels, which suggested that the microplastic altered the uptake route of a metal contaminant in a model fish species (Khan et al. 2015). Such ecotoxicological responses by microplastic-bound pollutants have been observed in other cases as well. The exposure of lugworms (Arenicola marina) to PVC particles containing TCS or nonylphenol (NP) resulted in lower survivorship, feeding rate, and phagocytic activity than that of the lugworms to clean PVC particles (Browne et al. 2013). Using Japanese medaka (Oryzias latipes) as model animals, the researchers indicated that the ingestion of LDPE microplastic with the environmental pollutants sorbed from San Diego Bay may cause hepatic toxicity and pathological responses (Rochman et al. 2013a). Pollutant exposure that was transferred by microplastic resulted in alterations in behaviour, wherein beachhoppers (Platorchestia smithi) that ingested PAH-contaminated PE beads displayed reduced jump height and survival rate (Tosetto et al. 2016). Moreover, microplastic could be a vector for the transport of pathogens. Viršek et al. (2017) demonstrated 28 bacterial species on the microplastic collected from North Adriatic, including Aeromonas salmonicida, which is a pathogenic bacterium that severely impacts fish aquaculture.

As a vector, the microplastic itself can be transferred through the trophic levels. Research has shown that microplastic is readily ingested by zooplanktons (Botterell et al. 2019), which is the main food source for many secondary consumers. Ingested microplastic could either be transferred up the trophic levels via predation (Farrell and Nelson 2013) or be egested from the food web and then very likely be re-ingested (Mazurais et al. 2015). There are relatively few studies on the estimation of the potential role of microplastic in transferring chemicals through the trophic structure. Lugworms that were exposed to PCB-contaminated PE showed an increase in bioaccumulation than the control group exposed to $\mathrm{PCB}$ alone (Besseling et al. 2013), which was in agreement with an earlier estimation of the bioavailability model discussed by Teuten et al. (2007). For the top predators, namely great shearwaters (Puffinus gravis) (Ryan 1988) and short-tailed shearwaters (Puffinus tenuirostris) (Tanaka et al. 2013), the concentrations of PCB and PBDE in the fat tissue and eggs showed a positive correlation to the amount of ingested plastic particles. However, note that the pollutants accumulated in the trophic structure may be transferred through the food item or prey itself rather than the microplastic vector. A 
Table 3 Types of microplastic-carried pollutants bioaccumulated in marine organisms

\begin{tabular}{|c|c|c|c|c|}
\hline Organism & Class & Pollutant & Microplastic & Reference \\
\hline Marine unicellular alga (Tetraselmis chuii) & Chlorodendrophyceae & Copper & $P E$ & $\begin{array}{l}\text { Davarpanah and Guilhermino } \\
\text { (2015) }\end{array}$ \\
\hline Lugworm (Arenicola marina) & Polychaeta & PCBs & PS & Besseling et al. (2013) \\
\hline Lugworms (Arenicola marina) & Polychaeta & Triclosan or nonylphenol & PVC & Browne et al. (2013) \\
\hline $\begin{array}{l}\text { Mediterranean mussel (Mytilus } \\
\text { galloprovincialis) }\end{array}$ & Bivalvia & HBCDs & PS & Jang et al. (2016) \\
\hline Peppery furrow shell (Scrobicularia plana) & Bivalvia & $\mathrm{BaP}$ & LDPE & O'Donovan et al. (2018) \\
\hline Zooplankton $^{\mathrm{a}}$ & a & PBDEs and PCBs & $P E$ and $P P$ & Yeo et al. (2020) \\
\hline Marine amphipod (Allorchestes Compressa) & Malacostraca & PBDEs & PE & Chua et al. (2014) \\
\hline Daphnia (Daphnia magna) & Branchiopoda & PCB & PS & Lin et al. (2019) \\
\hline Marine copepod (Acartia tonsa) & Maxillopoda & PAHs & PS & Sørensen et al. (2020) \\
\hline Marine copepod (Acartia tonsa) & Maxillopoda & Triclosan & PE & Syberg et al. (2017) \\
\hline Marine copepod (Calanus finmarchicus) & Hexanauplia & $\mathrm{PAHS}$ & PS & Sørensen et al. (2020) \\
\hline Beachhopper (Platorchestia smithi) & Malacostraca & PAHs & PE & Tosetto et al. (2016) \\
\hline $\begin{array}{l}\text { North Pacific lanternfish (Tarletonbeania } \\
\text { taylori) }\end{array}$ & Actinopterygii & $\begin{array}{l}\text { Lower chlorinated PCBs/ } \\
\text { pesticides }\end{array}$ & Plastic $^{a}$ & Gassel and Rochman (2019) \\
\hline Japanese medaka (Oryzias latipes) & Actinopterygii & PHAs, PCBs, and PBDEs & LDPE & Rochman et al. (2013a) \\
\hline zebrafish (Danio rerio) & Actinopterygii & $\mathrm{Ag}$ & PE & Khan et al. (2015) \\
\hline Rainbow trout (Oncorhynchus mykiss) & Actinopterygii & $\mathrm{Ag}$ & PE & Khan et al. (2017) \\
\hline Rainbow fish (Melanotaenia fluviatilis) & Actinopterygii & PBDEs & PP and PS & Wardrop et al. (2016) \\
\hline Rabbitfish (Siganus rivulatus) & Actinopterygii & PCB & DPE and PP & van der Hal et al. (2020) \\
\hline $\begin{array}{l}\text { Streaked shearwater (Calonectris } \\
\text { leucomelas) }\end{array}$ & Aves & PCB & PE & Tanaka et al. (2018) \\
\hline $\begin{array}{l}\text { Streaked shearwater (Calonectris } \\
\text { leucomelas) }\end{array}$ & Aves & PBDES & PE & Tanaka et al. (2015) \\
\hline Laysan albatross (Phoebastria immutabilis) & Aves & PCBs, PAHs, and pesticides & $P P$ and $P E$ & Rios et al. (2007) \\
\hline Northern fulmar (Fulmarus glacialis) & Aves & PCBs & Plastic $^{a}$ & Herzke et al. (2016) \\
\hline $\begin{array}{l}\text { Short-tailed shearwaters (Puffinus } \\
\text { tenuirostris) }\end{array}$ & Aves & PBDES & Plastic $^{a}$ & Tanaka et al. (2013) \\
\hline Great Shearwaters (Puffinus gravis) & Aves & PCBs & Plastic $^{a}$ & Ryan (1988) \\
\hline
\end{tabular}

${ }^{\mathrm{a}}$ No information

comparison with the concentrations of stomach plastic debris revealed that high PCB levels in northern fulmar (Fulmarus glacialis) are more likely to be contributed by their prey, instead of the plastics debris (Herzke et al. 2016). Moreover, in contrast to the vector role, microplastic could play a scavenger role that removes contaminants from individuals. Using ${ }^{13} \mathrm{C}$-labelled PBDE, the researchers showed that microplastic ingestion could both transfer and remove contaminants from sandhopper (Talitrus saltator), indicating a partial balance among the positive and the negative effects (Scopetani et al. 2018). Such conclusion is supported by the correlation between the concentrations of the hydrophobic organic compounds in the muscle tissue and the abundance of plastic particles in the stomachs of herring (Clupea harengus membras) collected along the Baltic Sea (Ogonowski et al. 2017).
However, most of the model analyses indicated that the ingestion of microplastic may not be an important pathway for the transfer of sorbed chemicals from the seawater to the ecosystem (Bakir et al. 2016; Gouin et al. 2011; Koelmans et al. 2014; Koelmans et al. 2016). Nevertheless, the extent of pollutants to be accumulated in the food web via the pathway of microplastic as a vector is still inconclusive. Furthermore, the chemical affinities of the plastics may influence their vector role (Koelmans et al. 2013). By measuring the desorption rates in artificial gut fluid, researchers have found that the intake of microplastic-bound hydrophobic organic compounds by organisms with similar gut retention times as fish varied according to the type of chemical. Moreover, the uptake of hexachlorocyclohexane $(\mathrm{HCH})$ via $\mathrm{PE}$ microplastic ingestion can be negligible as compared to the uptake via other exposure routes, such as 
water ventilation and food ingestion. However, microplastic ingestion can still increase the total uptake rate of pentachlorobenzene (PeCB) and hexachlorobenzene (HeCB) (Lee et al. 2019). Hence, future studies need to focus on the plastic debris that may have higher chemical affinities than the others. For example, PBAT has a greater vector effect than traditional materials because of its higher sorption and desorption capacities as an organic pollutant (Zuo et al. 2019).

\subsection{Pollutant bioaccumulation of microplastic and its factors}

The factors of bioaccumulation are desorption, organism internal environment, and retention time (Bakir et al. 2014; Barboza et al. 2018a; Ma et al. 2020a). Other bioaccumulation factors were similar to those that affect desorption, such as the size of microplastic and hydrophobicity (Ma et al. 2016). Bioaccumulation has been investigated and reported by several studies (Barboza et al. 2018a; Besseling et al. 2017; Chua et al. 2014; Ma et al. 2016; Rehse et al. 2018; Rochman et al. 2013b).

Bioaccumulation was prominently exhibited in a recent work by Barboza et al. wherein mercury concentrations in the gills and livers of juvenile European seabass Dicentrarchus labrax were doubled in the microplastic/ mercury mixture as compared to in the mercury-only setup (Barboza et al. 2018c). The presence of PE microplastic was also reported to increase the bioaccumulation of PBDE, PCB, and PAH (Rochman et al. 2013a). In another study, PBDE was bioaccumulated in the marine amphipod Allorchestes compressa in the presence of PE microplastic (Chua et al. 2014). Moreover, the congener hydrophobicity of PCB congeners showed varied bioaccumulation capacity in the marine lugworm Arenicola marina in the presence of PS (Besseling et al. 2013, 2017). Additionally, the presence of smaller PS microplastic $(50 \mathrm{~nm})$ increased the bioaccumulation of phenanthrene in planktonic crustacean Daphnia magna.

However, a contradiction was reported in a study when the microplastic PA/bisphenol mixture and the bisphenol-only setup did not exhibit dissimilar bioaccumulation or EC50 for Daphnia magna immobility (Rehse et al. 2018). The PA material could be a negligible vector of bisphenol. A similar finding was reported where the microplastic $\mathrm{PE} /$ phenanthrene mixture and the phenanthrene-only setup did not exhibit dissimilar EC50 for the immobilisation of Daphnia magna (Frydkjaer et al. 2017). Batel et al. (2016) reported biomagnification when microplastic was found to transfer benzo [a] pyrene $(\mathrm{BaP})$ from shrimp nauplii to zebrafish in an artificial aquatic food chain of zebrafish Danio rerio and brine shrimp nauplii Artemia sp.

Tourinho et al. suggested four possible scenarios of pollutant bioaccumulation introduced by microplastic into organisms, which were (1) strong sorption and strong desorption, (2) strong sorption and low desorption, (3) low sorption and strong desorption, and (4) low sorption and low desorption (Coffin et al. 2019; Magara et al. 2018; PaulPont et al. 2016; Tourinho et al. 2019; Ziajahromi et al. 2019). Firstly, microplastic with strong sorption and strong desorption acts as a vector for bioaccumulation. Pollutant uptake at high sorption levels can lead to high chemical desorption and increased bioaccumulation in an organism. A fast desorption rate was reported under gut conditions. For example, the 50-fold increment of microplastic (high sorption) led to higher venlafaxine concentrations (high desorption and bioaccumulation) in the liver of pond fish Misgurnus anguillicaudatus (Qu et al. 2018). In another example, 30-fold pollutant desorption was observed in the gut than in the seawater by Bakir et al. (Bakir et al. 2014; Coffin et al. 2019; Nor and Koelmans, 2019). Secondly, the scenario with strong sorption and low desorption may decrease bioavailability despite the pre-sorbing of microplastic with the pollutant. Examples that resembled this scenario include the low bioaccumulation of pre-sorbed fluoranthene and $\mathrm{Ag}$ by PE in mussels and zebrafish, respectively (Khan et al. 2015; Magara et al. 2018; Paul-Pont et al. 2016). Thirdly, the scenario with low sorption and strong desorption has a low sorbed fraction to desorb a high quantity of pollutants. This scenario resembles the low sorption of PBDE and bifenthrin on PE that are bioaccumulated equally or nearly completely in amphipods and midge Chironomus tepperi, respectively (Chua et al. 2014; Ziajahromi et al. 2019). Fourthly, the scenario with low sorption and low desorption typically ends with proportionally low bioaccumulation. For example, the low sorption of fluoranthene by microplastic was shown to produce low fluoranthene bioaccumulation in mussels Mytilus spp. (Paul-Pont et al. 2016). In this scenario, the main source of pollutants is typically through dietary means; hence, the distribution or bioavailability of pollutants would be the same with or without microplastic (Tourinho et al. 2019).

However, the ingestion of low-contaminated microplastic can lead to low bioaccumulation. As shown in Nor and Koelmans (2019), PCB were transferred from contaminated food to clean PE microplastic under a simulated gut condition. This suggests a fifth scenario, whereby instead of pre-sorbed microplastic, unsorbed or low-contaminated microplastic is ingested and then egested in a sorbed state caused by the strong sorption of pollutants in the organism's gut.

Furthermore, a delayed effect may occur, such as during or after depuration, and hence, it can be an important experimental step. For instance, excluding or including the remaining microplastic in the organism's gut at the end of an interval or experiment can cause disparities, particularly in comparative research (Paul-Pont et al. 2016; Tourinho et al. 2019). In a study on bioaccumulation in mussel 
Mytilus spp., the fluoranthene-only setup showed more toxicity before depuration, while higher fluoranthene concentration and histopathological damage were observed in the fluoranthene/microplastic mixture setup after depuration (Paul-Pont et al. 2016). Moreover, the combined setup of the pyrene/PE microplastic mixture showed the delayed mortality of fish Pomatoschistus microps (Oliveira et al. 2013). Nevertheless, the existing literature indicates that most studies have not reported a prominent bioaccumulation of pollutants by microplastic. According to Koelmans et al. the dietary pathway had a more direct bioaccumulation effect than microplastic (Koelmans et al. 2016).

The literature review revealed the impact of the differences in methodology toward the data. Researchers should consider the presence or absence of preincubation or pre-sorption, depuration period, combined co-exposure effect of a microplastic/pollutant mixture analysis, single effect of a pollutant-only analysis, and a dose-response analysis (Khan et al. 2015; Zhu et al. 2018a). Questions and challenges still exist concerning the bioaccumulation factors of microplastic-bound pollutants in organisms, as there are still gaps in this field that is yet to be thoroughly studied partially because of the varied internal environments of different organisms.

\subsection{Risks of pollutant bioaccumulation to the marine ecosystem and humans}

2.12.1 Risks toward the marine ecosystem

Other than the dangers of microplastic on its own, the risks of contaminants that are bound to the microplastic add to the combined effects of microplastic-pollutant complexes (Fig. 4). The contaminants were reported to desorb in the intestine of organisms followed by translocation to the circulatory system, intestinal epithelia, tissues, and organs such as liver. The combined effects of microplastic and the bioaccumulation of pollutants caused by microplastic-pollutant complexes include physiological stress, morphological abnormalities, immobilisation, neurotoxicity, oxidative damage, enzymatic dysregulation, reduced growth rate, reduced chlorophyll concentration, altered immune response, genotoxicity, and mortality (Barboza et al. 2018b; Batel et al. 2016; Khan et al. 2017; Kim et al. 2017a; Ma et al. 2016; Prata et al. 2018; Qiao et al. 2019; Qu et al. 2018; Syberg et al. 2017; Zhu et al. 2019). Heavy metals accumulate in brain and muscle tissues, causing the abovementioned neurotoxicity, oxidative damage, and enzymatic dysregulation, for example, the Ag accumulated in the intestinal mucous, mucosal epithelium, muscle layer, and serosa (Khan et al. 2017). In another example, bioaccumulated phenanthrene and its by-products caused joint system toxicity and immobilisation and were translocated into the daphnid tissue, gut, and carapace (Ma et al. 2016). The combined effects of microplastic and pollutants, such as metals, were also detected on marine fish and microalgae (Kim et al. 2017a).

However, there are conflicting findings about the biological toxicity of microplastic. For example, Rochman and co-workers reported the nil toxic effect of virgin microplastic against a fish cell line (Rochman et al.

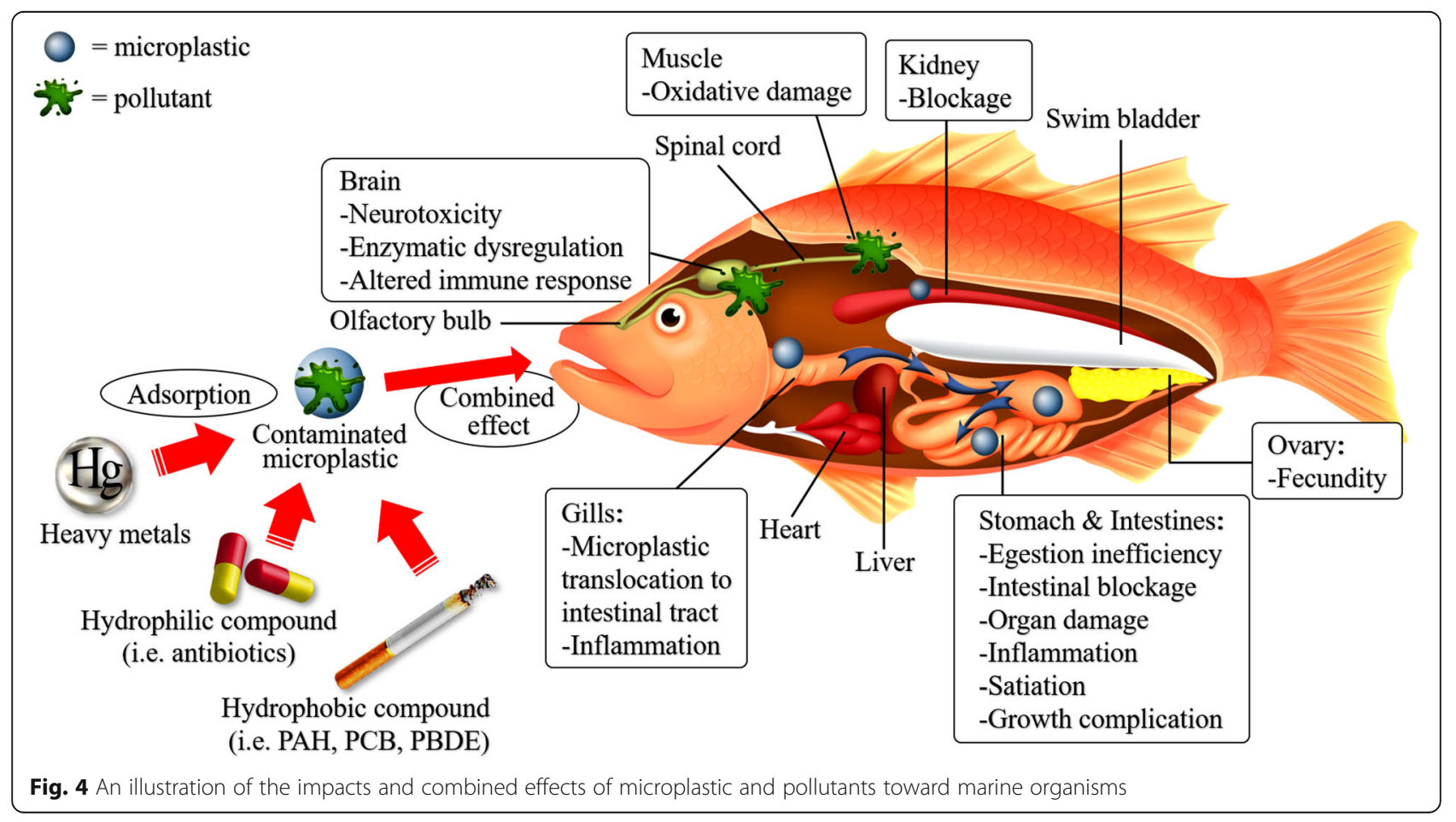


2014). In another study, the data of microplastic ingestion by the Antarctic krill Euphausia superba showed no mortality, toxicity, weight loss, or bioaccumulation (Dawson et al. 2018). Moreover, some research reported lowered concentration exposure and reduced short-term effects of bisphenol A (BPA) and PAH toward Daphnia magna (Kleinteich et al. 2018; Rehse et al. 2018).

\subsubsection{Risks toward humans}

Microplastic can be introduced to humans via inhalation or dietary routes through the consumption of seafood, such as fish and shellfish. Based on the abundances observed, it was estimated that Chinese shellfish consumers could be exposed to 100,000 microplastics each year (Wright and Kelly 2017). Furthermore, approximately 700 microplastics $/ \mathrm{kg}$ of microplastic, mainly PET and $\mathrm{PE}$, were found in 15 brands of commercial sea salt (Yang et al. 2015a). A recent study reported the presence of mainly PET and PP microplastics in all the eight human stool samples considered (Schwabl et al. 2019). The existing literature shows that microplastic is endangering our food safety and security as it contaminates the food meant for human consumption, but there is a lack of more recent studies regarding its direct clinical impacts on the human body.

The effect of microplastic against the health of organisms was investigated more than three decades ago. The literature indicates the possibility of microplastic to avoid the clearance mechanism, penetrate human or mammalian airways and deep lungs, become embedded or lodged, and induce chronic or acute inflammation (Pauly et al. 1998; Porter et al. 1999; Wright and Kelly 2017). An older report described microfibres as toxic to pulmonary cells and carcinogenic (Omenn et al. 1986). Investigations of microplastic in model mammalian systems indicated possible translocation from living cells to human organ systems, such as the lymphatic and circulatory systems and, thus, the ability to indirectly impact the immune system (Brown et al. 2001; Eldridge et al. 1989; Frohlich et al. 2009; Hodges et al. 1995; Jani et al. 1992; Rieux et al. 2005; Volkheimer 1975).

More recently, the health risks of microplastic have also been reported but are limited to the use of model organisms and relatively focused on the intoxication of organisms by the additives and pollutants leached from the microplastic than the microplastic itself (Costa et al. 2016). For example, a study analysed the in vitro gastrointestinal uptake of microplastic by using the human intestinal epithelial cell line and co-cultures mimicking intestinal M-cells and goblet cells, which showed no interference by the microplastic in terms of differentiation and activation (Stock et al. 2019). In another example, Crcontaminated PLA microplastic in the human digestive system was studied using the whole digestive system in vitro method, a systematic model that included the mouth, gastric, small intestine, and large intestine digestive phases (Liao and Yang 2020). The Cr levels were high in the gastric, small intestinal, and large intestinal phases. Furthermore, some pollutants, monomers, and additives in microplastic are POP and EDC that have been detected in the human body in a higher amount than expected by gut exposure, indicating substance introduction via other possible routes (Galloway 2015; Koelmans et al. 2016; Thompson et al. 2009; Vethaak and Leslie 2016). Additionally, long-term consumption of water contaminated with a plasticizer, phthalate, at levels above the US Environmental Protection Agency (USEPA) threshold $(<6 \mu \mathrm{g} /$ L) could cause liver and reproductive complications (Lambert et al. 2014; Martin and Voulvoulis 2009; USEPA 2012). Other health-threatening plastic additives (i.e. monomers, initiators, catalysts, emulsifiers, and stabilisers) include styrene, benzoyl peroxide, zeolites, and azobisisobutyronitrile (Todd et al. 2003). Carcinogenic PAH is among the environmental contaminants sorbed by microplastic in the ocean. These chemicals, now considered to be environmental contaminants, bioaccumulate in the fatty tissues of animals, which are eventually consumed by humans (Hwang et al. 2020). The literature review also demonstrated that the leaching of sorbed contaminants and the use of some additives and monomers contribute to the toxicity of microplastic-pollutant complexes toward living organisms, which include humans.

Although there are older studies describing the effect or existence of microplastic in humans and some relatively newer studies on the effect of microplastic conducted using model organisms or human cell lines as the reference, there is an urgent need for a more recent investigation on the possibility of microplastic causing any medical condition directly against human patients (Pauly et al. 1998; Porter et al. 1999; Stock et al. 2019). The lack of strong evidence of plastic leading to any direct detrimental effect on humans may allow continuous plastic production, consumption, and leaking of plastic debris into the oceans.

\subsection{Gaps in microplastic research and future outlook}

Microplastic is compromising our food safety because it pollutes the food meant for human consumption. Nonetheless, research on the impact of microplastic on the internal human body is limited. Moreover, the literature review revealed the importance of methodology differences in terms of data comparison and validity. For example, a few aspects in the methodology that should be contemplated include pre-incubation or pre-sorption, depuration, combined co-exposure of a microplastic and pollutant mixture, pollutant-only effect analysis, and dose-response analysis. Furthermore, because of the lack of standardised methods, studies have adopted different 
microplastic sampling and analytical methods (Jiang et al. 2020). The different definitions, sampling methods, and analytical methods of microplastic could affect the comparability and consistency of data among different researchers.

Furthermore, mixed findings from the past literature suggest that the effect of microplastic ageing on pollutant sorption capacity depends on the type of pollutant or microplastic, and the gradual changes in their chemical bonds, forces, or interactions over time. Although some studies have reported the lack of negative effects from microplastic, other reports on the hazards of microplastic toward the environment should not be ignored. Additionally, questions still exist concerning the bioaccumulation factors of microplastic-bound pollutants in organisms, as internal environments vary from one organism to another.

The possible future approaches that can alleviate microplastic pollution include the collection and dissemination of insightful scientific data and facts, public awareness, stakeholder engagement, and the incorporation of environmentally friendly, alternative polymeric material (Gong et al. 2019; Govindasamy et al. 2019; Zuo et al. 2019). However, an in-depth investigation is required to confirm the biological, physical, or chemical properties that are responsible for the sorption capacity of a microplastic with a specific pollutant. Currently, the biofilm presence on microplastic has been reported to be one of the factors that can contribute to pollutant sorption by microplastic. Furthermore, the maximum sorption capacity of a material can become a limiting factor of toxicity. Moreover, a broad comparative or statistical approach can link the associative patterns of microplastic and pollutants with environmental conditions, such as $\mathrm{pH}$ and salinity. Research in the direction of investigating the chemical interactions between microplastics, pollutants, and the environment can disclose new indirect factors of pollutant sorption by microplastic. Additionally, future studies need to focus on the plastic debris that may have higher chemical affinities than the others. For example, PBAT has a greater vector effect than traditional materials because of its higher sorption and desorption capacities as an organic pollutant. Moreover, instead of that of presorbed microplastic, the potential of unsorbed or lowcontaminated microplastic to be egested in a sorbed state and carry pollutants out of the gut of organisms is also worth investigating in future experiments. Therefore, future microplastic research is expected to move toward achieving a deeper understanding of the factors related to pollutant sorption and bioaccumulation by microplastic as well as standardising the protocols involved in microplastic research.
Microplastic pollution has been a long-standing cause for concern with respect to environmental engineering, ecology, and materials sciences. However, to solve the problems associated with microplastic pollution, at least accumulatively at a small scale, research efforts toward understanding plastic compositions, characterising plastics, tracing the sources and sinks of plastics, grasping the complex microplasticenvironment interactions, implementing policies, biotechnological approaches, and infrastructure and technology advances are required in combination (Hale et al. 2020; Barceló and Picó 2020; Agamuthu et al. 2019). This may include ways of reducing plastic waste materials at the source (i.e. recycling and compostable packaging), reducing microplastic leakage from waste treatment facilities, or increasing the use of biodegradable or renewable-sourced plastic (Amelia et al. 2020; Neufeld et al. 2016; Zhang et al. 2020b). Systematic, innovative research and approaches are needed to minimise microplastic contamination.

\section{Conclusions}

In conclusion, the microplastics commonly found to pollute the marine environment were generally of the fibre or fragment type, contained PE or PP material, and were typically contributed by anthropogenic, urban, fishery, or marine activities. The currently known factors of microplastic bioavailability toward organisms are the size, colour, density, morphology, and mobility of microplastic, as well as the species, morphology, and physiology of organisms. Additionally, the factors known to affect the pollutant sorption of microplastic are the colour, density, age, and chemical properties of the microplastic, type of pollutant, biofilm presence, and environmental conditions such as dissolved organic matter, $\mathrm{pH}$, and salinity. Understanding, providing further evidence, and disseminating the currently known factors of microplastic pollution, bioavailability, sorption, and bioaccumulation will be constructive and valuable in alleviating the global microplastic pollution crisis.

Moreover, the sorption, aggregation, ingestion, retention, egestion, reingestion, and release of chemicals present potential mechanisms for the transport of environmental contaminants (POP, PAH, and EDC), hydrophobic organic compounds, and metals. The literature review revealed that the chief and direct factor of pollutant sorption by microplastic is chemical interaction. Research in the direction of investigating the chemical interactions between microplastics, pollutants, and the environment can disclose new indirect factors of pollutant sorption by microplastic. Overall, the clear extent of pollutants to be accumulated in the food web via the pathway of microplastic as a vector is still inconclusive. For example, the chemical affinities of the plastics may 
influence their vector role, and thus, future studies need to focus on the plastic debris that may have higher chemical affinities than the others. Numerous diverse factors, such as the species of organisms and the type of pollutants, govern the sorption and bioaccumulation (i.e. desorption) of pollutants in the presence of microplastic. It is still a research challenge to achieve a clearer and more comprehensive understanding of the underlying factors influencing the sorption and bioaccumulation behaviours. Progressive and objective research coupled with management could determine the future production, consumption, and leakage of plastic debris into the oceans.

\section{Abbreviations \\ 4MBC: 4-Methylbenzylidene camphor; AMX: Amoxicillin; BaP: Benzo [a]pyrene; CBZ: Carbamazepine; CIP: Ciprofloxacin hydrochloride; \\ EDC: Endocrine-disrupting chemical; EE2: 17a-Ethinylestradiol; EVA: Ethylene- vinyl acetate; FTIR: Fourier-transform infrared spectroscopy; \\ HBCD: Hexabromocyclododecane; HCH: Hexachlorocyclohexane; HDPE: High- density polyethylene; HeCB: Hexachlorobenzene; LDPE: Low-density polyethylene; NP: Nonylphenol; PA: Polyamide; PAH: Polycyclic aromatic hydrocarbon; PB: Polybutylene; PBAT: Polybutylene adipate terephthalate; PBDE: Polybrominated diphenyl ether; PCB: Polychlorinated biphenyl; PE: Polyethylene; PeCB: Pentachlorobenzene; PES: Polyethersulfone; PET: Polyethylene terephthalate; PFAA: Perfluoroalkyl acids; PFOS: Perfluorooctanesulfonate; PFOSA: Perfluorooctanesulfonamide; PMMA: Poly (methyl methacrylate); POP: Persistent organic pollutant; PP: Polypropylene; PPCP: Pharmaceuticals personal care product; PS: Polystyrene; PU: Polyurethane; PVA: Polyvinyl acetate; PVC: Polyvinyl chloride; SBR: Styrene butadiene rubber; SDZ: Sulfadiazine; TC: Tetracycline; TCS: Triclosan; TMP: Trimethoprim; TYL: Tylosin; USEPA: US Environmental Protection Agency}

\section{Acknowledgements}

The authors thank Mr. Arularasu Muthaliar Tamothran and the anonymous reviewers for their constructive comments to improve the manuscript.

\section{Authors' contributions}

KB proposed the topic, conceived and designed the article. TSMA, YTS, WMAWMK, and HP carried out the review of literature and writing. MCO proofread and helped with the interpretation of review of literature. All authors read and approved the final manuscript.

\section{Authors' information}

TSMA is a graduate student in Universiti Malaysia Terengganu, Malaysia. KB, $\mathrm{MCO}$, and YTS are her advisors. WMAWMK is a senior lecturer in Universiti Malaysia Terengganu, Malaysia. HJP is an assistant researcher in Institute of Earth Sciences, National Taiwan Ocean University, Taiwan.

\section{Funding}

Preparation of this review was partially supported by the Postgraduate Research Grant (PGRG), Universiti Malaysia Terengganu (UMT) (55193/1) and Specific-Topic Research Projects by the Ministry of Science and Technology (MOST), Taiwan (MOST 109-2621-M-019-001).

\section{Availability of data and materials}

Not applicable. Data sharing not applicable to this article as no datasets were generated or analysed.

\section{Competing interests}

The authors declare that they have no competing interest.

\section{Author details}

${ }^{1}$ Faculty of Science and Marine Environment, Universiti Malaysia Terengganu, 21030 Kuala Nerus, Terengganu, Malaysia. ${ }^{2}$ Microplastic Research Interest Group, Universiti Malaysia Terengganu, 21030 Kuala Nerus, Terengganu,
Malaysia. ${ }^{3}$ Ocean Pollution \& Ecotoxicology Research Group, Universiti Malaysia Terengganu, 21030 Kuala Nerus, Terengganu, Malaysia. ${ }^{4}$ Institute of Marine Biology, National Taiwan Ocean University, Keelung 20224, Taiwan. ${ }^{5}$ Center of Excellence for the Oceans, National Taiwan Ocean University, Keelung 20224, Taiwan. ${ }^{6}$ Institute of Earth Sciences, College of Ocean Science and Resource, National Taiwan Ocean University, Keelung 20224, Taiwan. ${ }^{7}$ Center of Excellence for Ocean Engineering, College of Engineering, National Taiwan Ocean University, Keelung 20224, Taiwan. Institute of Marine Biotechnology, Universiti Malaysia Terengganu, 21030 Kuala Nerus, Terengganu, Malaysia. ${ }^{9}$ Malaysian Institute of Pharmaceuticals and Nutraceuticals, National Institutes of Biotechnology Malaysia, 11700 Penang, Malaysia.

Received: 11 May 2020 Accepted: 28 December 2020

Published online: 22 January 2021

\section{References}

Abbasi S, Soltani N, Keshavarzi B, Moore F, Turner A, Hassanaghaei M (2018) Microplastics in different tissues of fish and prawn from the Musa estuary, Persian gulf. Chemosphere 205:80-87

Absorb (2020) Lexico.com Retrieved from https:/www.lexico.com/definition/ absorb Accessed on 17 August 2020.

Adsorb (2020) Lexico.com Retrieved from https:/www.lexico.com/definition/ adsorb Accessed on 17 August 2020.

Agamuthu P, Mehran SB, Norkhairah A, Norkhairiyah A (2019) Marine debris: a review of impacts and global initiatives. Waste Manag Res 37:987-1002

Akarsu C, Kumbur H, Gökdağ K, Kıdeyş AE, Sanchez-Vidal A (2020) Microplastics composition and load from three wastewater treatment plants discharging into Mersin Bay, north eastern Mediterranean Sea. Mar Pollut Bull 150:110776

Aliabad MK, Nassiri M, Kor K (2019) Microplastics in the surface seawaters of Chabahar Bay, Gulf of Oman (Makran coasts). Mar Pollut Bull 143:125-133

Alimi OS, Budarz JF, Hernandez LM, Tufenkji N (2018) Microplastics and nanoplastics in aquatic environments: aggregation, deposition, and enhanced contaminant transport. Environ Sci Technol 52:1704-1724

Amelia TSM, Govindasamy S, Tamothran AM, Vigneswari S, Bhubalan K (2019) Applications of PHA in agriculture. In: Kalia VC (ed) Biotechnological applications of polyhydroxyalkanoates. Springer, Singapore, pp 347-361

Amelia TSM, Sukri SNF, Jaapar AN, Md Amin R, Bhubalan K (2020) Uptake and egestion of polyhydroxyalkanoate microbeads in the marine copepod Nitokra lacustris pacifica. J Sustain Sci Manag 15:45-53

Amin RM, Sohaimi ES, Anuar ST, Bachok Z (2020) Microplastic ingestion by zooplankton in Terengganu coastal waters, southern South China Sea. Mar Pollut Bull 150:110616

Andrady AL (2011) Microplastics in the marine environment. Mar Pollut Bull 62: 1596-1605

Antunes JC, Frias JGL, Micaelo AC, Sobral P (2013) Resin pellets from beaches of the Portuguese coast and adsorbed persistent organic pollutants. Estuar Coast Shelf Sci 130:62-69

Auta HS, Emenike CU, Fauziah SH (2017) Distribution and importance of microplastics in the marine environment: a review of the sources, fate, effects, and potential solutions. Environ Int 102:165-176

Auta HS, Emenike CU, Jayanthi B, Fauziah SH (2018) Growth kinetics and biodeterioration of polypropylene microplastics by bacillus sp. and Rhodococcus sp. isolated from mangrove sediment. Mar Pollut Bull 127:1521

Avio CG, Gorbi S, Regoli F (2017) Plastics and microplastics in the oceans: from emerging pollutants to emerged threat. Mar Environ Res 128:2-11

Baini M, Fossi MC, Galli M, Caliani I, Campani T, Finoia MG, Panti C (2018) Abundance and characterization of microplastics in the coastal waters of Tuscany (Italy): the application of the MSFD monitoring protocol in the Mediterranean Sea. Mar Pollut Bull 133:543-552

Bakir A, O'Connor IA, Rowland SJ, Hendriks AJ, Thompson RC (2016) Relative importance of microplastics as a pathway for the transfer of hydrophobic organic chemicals to marine life. Environ Pollut 219:56-65

Bakir A, Rowland SJ, Thompson RC (2012) Competitive sorption of persistent organic pollutants onto microplastics in the marine environment. Mar Pollut Bull 64:2782-2789

Bakir A, Rowland SJ, Thompson RC (2014) Transport of persistent organic pollutants by microplastics in estuarine conditions. Estuar Coast Shelf Sci 140: $14-21$ 
Baldwin BS (1995) Selective particle ingestion by oyster larvae (Crassostrea virginica) feeding on natural seston and cultured algae. Mar Biol 123:95-107

Barboza LGA, Vethaak AD, Lavorante BR, Lundebye AK, Guilhermino L (2018a) Marine microplastic debris: an emerging issue for food security, food safety and human health. Mar Pollut Bull 133:336348

Barboza LGA, Vieira LR, Branco V, Carvalho C, Guilhermino L (2018b) Microplastics increase mercury bioconcentration in gills and bioaccumulation in the liver, and cause oxidative stress and damage in Dicentrarchus labrax juveniles. Sci Rep 8:15655

Barboza LGA, Vieira LR, Branco V, Figueiredo N, Carvalho F, Carvalho C, Guilhermino L (2018c) Microplastics cause neurotoxicity, oxidative damage and energy-related changes and interact with the bioaccumulation of mercury in the European seabass, Dicentrarchus labrax (Linnaeus 1758). Aquat Toxicol 195:49-57

Barceló D, Picó Y (2020) Case studies of macro- and microplastics pollution in coastal waters and rivers: is there a solution with new removal technologies and policy actions? Case studies in chemical and environmental engineering, p 100019

Batel A, Linti F, Scherer M, Erdinger L, Braunbeck T (2016) Transfer of benzo a pyrene from microplastics to Artemia nauplii and further to zebrafish via a trophic food web experiment: CYP1A induction and visual tracking of persistent organic pollutants. Environ Toxicol Chem 35:1656-1666

Belzagui F, Crespi M, Álvarez A, Gutiérrez-Bouzán C, Vilaseca M (2019) Microplastics' emissions: microfibers' detachment from textile garments. Environ Pollut 248:1028-1035

Besseling E, Foekema EM, Van Den Heuvel-Greve MJ, Koelmans AA (2017) The effect of microplastic on the uptake of chemicals by the lugworm Arenicola marina (L.) under environmentally relevant exposure conditions. Environ Sci Technol 51:8795-8804

Besseling E, Foekema EM, Van Franeker JA, Leopold MF, Kühn S, Rebolledo ELB, Heße E, Mielke L, IJzer J, Kamminga P, Koelmans AA (2015) Microplastic in a macro filter feeder: humpback whale Megaptera novaeangliae. Mar Pollut Bull 95:248-252

Besseling E, Quik JTK, Sun M, Koelmans AA (2016) Fate of nano- and microplastic in freshwater systems: a modeling study. Environ Pollut 220:540

Besseling E, Wegner A, Foekema EM, van den Heuvel-Geve MJ, Koelmans AA (2013) Effects of microplastic on fitness and PCB bioaccumulation by the lugworm Arenicola marina (L.). Environ Sci Technol 47:593-600

Betts K (2008) Why small plastic particles may pose a big problem in the oceans. ACS Publications

Boerger CM, Lattin GL, Moore SL, Moore CJ (2010) Plastic ingestion by planktivorous fishes in the North Pacific central gyre. Mar Pollut Bull 60:22752278

Bolto B, Xie Z (2019) The use of polymers in the flotation treatment of wastewater. Processes 7:374

Botterell ZL, Beaumont N, Dorrington T, Steinke M, Thompson RC, Lindeque PK (2019) Bioavailability and effects of microplastics on marine zooplankton: a review. Environ Pollut 245:98-110

Brandon AM, Gao SH, Tian R, Ning D, Yang SS, Zhou J, Wu WM, Criddle CS (2018) Biodegradation of polyethylene and plastic mixtures in mealworms (larvae of Tenebrio molitor) and effects on the gut microbiome. Environ Sci Technol 52: 6526-6533

Brennecke D, Duarte B, Paiva F, Cacador I, Canning-Clode J (2016) Microplastics as vector for heavy metal contamination from the marine environment. Estuar Coast Shelf Sci 178:189-195

Brown DM, Wilson MR, MacNee W, Stone V, Donaldson K (2001) Size-dependent proinflammatory effects of ultrafine polystyrene particles: a role for surface area and oxidative stress in the enhanced activity of ultrafines. Toxicol Appl Pharmacol 175:191-199

Browne MA, Niven SJ, Galloway TS, Rowland SJ, Thompson RC (2013) Microplastic moves pollutants and additives to worms, reducing functions linked to health and biodiversity. Curr Biol 23:2388-2392

Camins E, Haan WP, Salvo VS, Canals M, Raffard A, Sanchez-Vidal A (2020) Paddle surfing for science on microplastic pollution. Sci Total Environ 709:136178

Caruso G (2019) Microplastics as vectors of contaminants. Mar Pollut Bull 146: 921-924

Castillo A, Al-Maslamani I, Obbard JP (2016) Prevalence of microplastics in the marine waters of Qatar's exclusive economic zone (EEZ). MICRO 2016. Fate and impact of microplastics in marine ecosystems, p 112
Chen M, Jin M, Tao P, Wang Z, Xie W, Yu X, Wang K (2018) Assessment of microplastics derived from mariculture in Xiangshan Bay, China. Environ Pollut 242:1146-1156

Cheung LTO, Lui CY, Fok L (2018) Microplastic contamination of wild and captive flathead grey mullet (Mugil cephalus). Int J Environ Res Public Health 15:597

Chua EM, Shimeta J, Nugegoda D, Morrison PD, Clarke BO (2014) Assimilation of polybrominated diphenyl ethers from microplastics by the marine amphipod, Allorchestes compressa. Environ Sci Technol 48:8127-8134

Clark JR, Cole M, Lindeque PK, Fileman E, Blackford J, Lewis C, Lenton TM, Galloway TS (2016) Marine microplastic debris: a targeted plan for understanding and quantifying interactions with marine life. Front Ecol Environ 14:317-324

Coffin S, Huang GY, Lee I, Schlenk D (2019) Fish and seabird gut conditions enhance desorption of estrogenic chemicals from commonly-ingested plastic items. Environ Sci Technol 53:4588-4599

Cole M, Lindeque P, Halsband C, Galloway TS (2011) Microplastics as contaminants in the marine environment: a review. Mar Pollut Bull 62:25882597

Cole M, Lindeque PK, Fileman E, Clark J, Lewis C, Halsband C, Galloway TS (2016) Microplastics alter the properties and sinking rates of zooplankton faecal pellets. Environ Sci Technol 50:3239-3246

Conley K, Clum A, Deepe J, Lane H, Beckingham B (2019) Wastewater treatment plants as a source of microplastics to an urban estuary: removal efficiencies and loading per capita over one year. Water Research X 3:100030

Cordova MR, Purwiyanto AIS, Suteja Y (2019) Abundance and characteristics of microplastics in the northern coastal waters of Surabaya, Indonesia. Mar Pollut Bull 142:183-188

Corradini F, Meza P, Eguiluz R, Casado F, Huerta-Lwanga E, Geissen V (2019) Evidence of microplastic accumulation in agricultural soils from sewage sludge disposal. Sci Total Environ 671:411-420

Costa JP, Santos PSM, Duarte AC, Rocha-Santos T (2016) (Nano) plastics in the environment - sources, fates and effects. Sci Total Environ 566-567:15-26

Courtene-Jones W, Quinn B, Gary SF, Mogg AOM, Narayanaswamy BE (2017) Microplastic pollution identified in deep-sea water and ingested by benthic invertebrates in the Rockall trough, North Atlantic Ocean. Environ Pollut 231: $271-280$

Dai Z, Zhang H, Zhou Q, Tian Y, Chen T, Tu C, Fu C, Luo Y (2018) Occurrence of microplastics in the water column and sediment in an inland sea affected by intensive anthropogenic activities. Environ Pollut 242:1557-1565

Davarpanah E, Guilhermino L (2015) Single and combined effects of microplastics and copper on the population growth of the marine microalgae Tetraselmis chuii. Estuar Coast Shelf Sci 167:269-275

Dawson A, Huston W, Kawaguchi S, King C, Cropp R, Wild S, Eisenmann P, Townsend K, Nash SB (2018) Uptake and depuration kinetics influence microplastic bioaccumulation and toxicity in Antarctic krill Euphausia superba. Environ Sci Technol 52:3195-3201

Devi R, Rajesh Kannan V, Nivas D, Kannan K, Chandru S, Robert Antony A (2015) Biodegradation of HDPE by Aspergillus spp. from marine ecosystem of gulf of Mannar, India. Mar Pollut Bull 96:32-40

Duis K, Coors A (2016) Microplastics in the aquatic and terrestrial environment: sources (with a specific focus on personal care products), fate and effects. Environ Sci Eur 28:2

Eldridge JH, Meulbroek JA, Staas JK, Tice TR, Gilley RM (1989) Vaccine-containing biodegradable microspheres specifically enter the gut-associated lymphoid tissue following oral administration and induce a disseminated mucosal immune response. In: Atassi MZ (ed) Immunobiology of proteins and peptides V: vaccines mechanisms, design, and applications. Springer, pp $191-202$

Enders K, Lenz R, Stedmon CA, Nielsen TG (2015) Abundance, size and polymer composition of marine microplastics $\geq 10 \mu \mathrm{m}$ in the Atlantic Ocean and their modelled vertical distribution. Mar Pollut Bull 100:70-81

Endo S, Grathwohl P, Schmidt TC (2008) Absorption or adsorption? Insights from molecular probes $n$-alkanes and cycloalkanes into modes of sorption by environmental solid matrices. Environ Sci Technol 42:3989-3995

Farrell P, Nelson K (2013) Trophic level transfer of microplastic: Mytilus edulis (L.) to Carcinus maenas (L.). Environ Pollut 177:1-3

Ferreira M, Thompson J, Paris A, Rohindra D, Rico C (2020) Presence of microplastics in water, sediments and fish species in an urban coastal environment of Fiji, a Pacific small island developing state. Mar Pollut Bull 153:110991 
Fisner M, Majer A, Taniguchi S, Bícego M, Turra A, Gorman D (2017) Color spectrum and resin-type determine the concentration and composition of polycyclic aromatic hydrocarbons (PAHs) in plastic pellets. Mar Pollut Bull 122:323-330

Fotopoulou KN, Karapanagioti HK (2012) Surface properties of beached plastic pellets. Mar Environ Res 81:70-77

Frias JP, Antunes JC, Sobral P (2013) Local marine litter survey - a case study in Alcobaça municipality, Portugal. J Integrated Coast Zone Manag 13:169-179

Fries E, Zarfl C (2012) Sorption of polycyclic aromatic hydrocarbons (PAHs) to low and high density polyethylene (PE). Environ Sci Pollut Res Int 19:1296-1304

Frohlich E, Samberger C, Kueznik T, Absenger M, Roblegg E, Zimmer A, Pieber TR (2009) Cytotoxicity of nanoparticles independent from oxidative stress. J Toxicol Sci 34:363-375

Frydkjaer CK, Iversen N, Roslev P (2017) Ingestion and egestion of microplastics by the Cladoceran daphniamagna: effects of regular and irregular shaped plastic and sorbed phenanthrene. Bull Environ Contam Toxicol 99:655-661

Galgani F, Hanke G, Maes T (2015) Global distribution, composition and abundance of marine litter. In: Bergmann M, Gutow L, Klages M (eds) Marine anthropogenic litter. Springer, Cham, pp 29-56

Galloway (2015) Micro- and nano-plastics and human health. In: Bergmann M, Gutow L, Klages M (eds) Marine anthropogenic litter. Springer, Cham, pp 343-366

Gambardella C, Morgana S, Ferrando S, Bramini M, Piazza V, Costa E, Garaventa F, Faimali M (2017) Effects of polystyrene microbeads in marine planktonic crustaceans. Ecotoxicol Environ Saf 145:250-257

Gassel M, Rochman CM (2019) The complex issue of chemicals and microplastic pollution: a case study in North Pacific lanternfish. Environ Pollut 248:1000-1009

Gieré R, Sommer F, Dietze V, Baum A, Gilge S, Sauer J, Maschowski C (2018) Tirewear particles as a major component of microplastics in the environment. Geol Soc Am 50

Gong W, Jiang M, Han P, Liang G, Zhang T, Liu G (2019) Comparative analysis on the sorption kinetics and isotherms of fipronil on nondegradable and biodegradable microplastics. Environ Pollut 254:112927

Göpferich A (1995) Mechanisms of polymer degradation and erosion. Biomaterials 17:103

Gouin T, Roche N, Lohmann R, Hodges G (2011) A thermodynamic approach for assessing the environmental exposure of chemicals absorbed to microplastic. Environ Sci Technol 45:1466-1472

Govindasamy S, Syafiq IM, Amirul AAA, Amin RM, Bhubalan K (2019) Dataset on controlled production of polyhydroxyalkanoate-based microbead using double emulsion solvent evaporation technique. Data Brief 23:103675

Greven AC, Merk T, Karagöz F, Mohr K, Klapper M, Jovanović B, Palić D (2016) Polycarbonate and polystyrene nanoplastic particles act as stressors to the innate immune system of fathead minnow (Pimephales promelas). Environ Toxicol Chem 35:3093-3310

Gündoğdu S, Çevik C, Güzel E, Kilercioğlu S (2018) Microplastics in municipal wastewater treatment plants in Turkey: a comparison of the influent and secondary effluent concentrations. Environ Monit Assess 190:626

Guo J, Huang X, Xiang L, Wang Y, Li Y, Li H, Cai Q, Mo C, Wong M (2020) Source, migration and toxicology of microplastics in soil. Environ Int 137:105263

Guo X, Wang X, Zhou X, Kong X, Tao S, Xing B (2012) Sorption of four hydrophobic organic compounds by three chemically distinct polymers: role of chemical and physical composition. Environ Sci Technol 46:7252-7259

Guo XT, Pang JW, Chen SY, Jia HZ (2018) Sorption properties of tylosin on four different microplastics. Chemosphere 209:240-245

Guzzetti E, Sureda A, Tejada S, Faggio C (2018) Microplastic in marine organism: environmental and toxicological effects. Environ Toxicol Pharmacol 64:164-171

Haghi BN, Banaee M (2017) Effects of micro-plastic particles on paraquat toxicity to common carp (Cyprinus carpio): biochemical changes. Int J Environ Sci Technol 14:521-530

Hale RC, Seeley ME, La Guardia MJ, Mai L, Zeng EY (2020) A global perspective on microplastics. J Geophys Res Oceans 125:e2018JC014719

Hartmann NB, Rist S, Bodin J, Jensen LH, Schmidt SN, Mayer P, Meibom A, Baun A (2017) Microplastics as vectors for environmental contaminants: exploring sorption, desorption, and transfer to biota. Integr Environ Assess Manag 13: 488-493

He P, Chen L, Shao L, Zhang H, Lü F (2019) Municipal solid waste (MSW) landfill: a source of microplastics? -evidence of microplastics in landfill leachate. Water Res 159:38-45

Hernandez E, Nowack B, Mitrano DM (2017) Polyester textiles as a source of microplastics from households: a mechanistic study to understand microfiber release during washing. Environ Sci Technol 51:7036-7046
Herzke D, Anker-Nilssen T, Nøst TH, Götsch A, Christensen-Dalsgaard S, Langset M et al (2016) Negligible impact of ingested microplastics on tissue concentrations of persistent organic pollutants in northern fulmars off coastal Norway. Environ Sci Technol 50:1924-1933

Hodges GM, Carr EA, Hazzard RA, Carr KE (1995) Uptake and translocation of microparticles in small intestine. Morphology and quantification of particle distribution. Dig Dis Sci 40:967-975

Holmes LA, Turner A, Thompson RC (2012) Adsorption of trace metals to plastic resin pellets in the marine environment. Environ Pollut 160:42-48

Holmes LA, Turner A, Thompson RC (2014) Interactions between trace metals and plastic production pellets under estuarine conditions. Mar Chem 167:25-32

Horton A, Walton A, Spurgeon DJ, Lahive E, Svendsen C (2017) Microplastics in freshwater and terrestrial environments: evaluating the current understanding to identify the knowledge gaps and future research priorities. Sci Total Environ 586:127-141

Horton AA, Svendsen C, Williams RJ, Spurgeon DJ, Lahive E (2016) Large microplastic particles in sediments of tributaries of the river Thames, UK abundance, sources and methods for effective quantification. Mar Pollut Bull 114:218-226

Howell EA, Bograd SJ, Morishige C, Seki MP, Polovina JJ (2012) On North Pacific circulation and associated marine debris concentration. Mar Pollut Bull 65: $16-22$

Hu JQ, Yang SZ, Guo L, Xu X, Yao T, Xie F (2017) Microscopic investigation on the adsorption of lubrication oil on microplastics. J Mol Liq 227:351-355

Hu Y, Gong M, Wang J, Bassi A (2019) Current research trends on microplastic pollution from wastewater systems: a critical review. Rev Environ Sci Biotechnol 18:207-230

Huffer T, Hofmann T (2016) Sorption of non-polar organic compounds by microsized plastic particles in aqueous solution. Environ Pollut 214:194-201

Huffer T, Weniger AK, Hofmann T (2018) Sorption of organic compounds by aged polystyrene microplastic particles. Environ Pollut 236:218-225

Hwang J, Choi D, Han S, Jung SY, Choi J, Hong J (2020) Potential toxicity of polystyrene microplastic particles. Sci Rep 10:7391

Ivleva NP, Wiesheu AC, Niessner R (2017) Microplastic in aquatic ecosystems. Angew Chem Int Ed 56:1720-1739

Jabeen K, Li B, Chen Q, Su L, Wu C, Hollert H, Shi H (2018) Effects of virgin microplastics on goldfish (Carassius auratus). Chemosphere 213:323-332

Jambeck JR, Geyer R, Wilcox C, Siegler TR, Perryman M, Andrady A, Narayan R, Law KL (2015) Plastic waste inputs from land into the ocean. Science 347: 768-771

Jang M, Shim WJ, Han GM, Rani M, Song YK, Hong SH (2016) Styrofoam debris as a source of hazardous additives for marine organisms. Environ Sci Technol 50:4951-4960

Jani PU, McCarthy DE, Florence AT (1992) Nanosphere and microsphere uptake via Peyer's patches: observation of the rate of uptake in the rat after a single oral dose. Int J Pharm 86:239-246

Jeong CB, Won EJ, Kang HM, Lee MC, Hwang DS, Hwang UK, Zhou B, Souissi S, Lee SJ, Lee JS (2016) Microplastic size-dependent toxicity, oxidative stress induction, and p-JNK and p-p38 activation in the monogonont rotifer (Brachionus koreanus). Environ Sci Technol 50:8849-8857

Jiang Y, Yang F, Zhao Y, Wang J (2020) Greenland Sea gyre increases microplastic pollution in the surface waters of the Nordic seas. Sci Total Environ 712:136484

Jovanovic B (2017) Ingestion of microplastics by fish and its potential consequences from a physical perspective. Integr Environ Assess Manag 13 510-515

Jun Y, Yu Y, Wei-Min W, Jiao Z, Lei J (2014) Evidence of PE biodegradation by bacterial strains frothe guts of plastic-eating waxworms. Environ Sci Technol 48:13776-13784

Kanhai LDK, Gårdfeldt K, Lyashevska O, Hassellöv M (2018) Microplastics in subsurface waters of the Arctic Central Basin. Mar Pollut Bull 130:8-18

Karapanagioti HK, Klontza I (2008) Testing phenanthrene distribution properties of virgin plastic pellets and plastic eroded pellets found on Lesvos island beaches (Greece). Mar Environ Res 65:283-290

Katsnelson A (2015) News feature: microplastics present pollution puzzle. PNAS 112:5547-5549

Kazour M, Jemaa S, Issa C, Khalaf G, Amara R (2019) Microplastics pollution along the Lebanese coast (eastern Mediterranean Basin): occurrence in surface water, sediments and biota samples. Sci Total Environ 696:133933

Kedzierski M, D'Almeida M, Magueresse A, Le Grand A, Duval H, Cesar G, Sire O, Bruzaud S, Tilly VL (2018) Threat of plastic ageing in marine environment. Adsorption/desorption of micropollutants. Mar Pollut Bull 127:684-694 
Khalik WMAWM, Ibrahim YS, Anuar ST, Govindasamy S, Baharuddin NF (2018) Microplastics analysis in Malaysian marine waters: a field study of Kuala Nerus and Kuantan. Mar Pollut Bull 135:451-457

Khan FR, Boyle D, Chang E, Bury NR (2017) Do PE microplastic beads alter the intestinal uptake of $\mathrm{Ag}$ in rainbow trout Oncorhynchus mykiss? Analysis of the microplastics vector effect using in vitro gut sacs. Environ Pollut 231:200-206

Khan FR, Syberg K, Shashoua Y, Bury NR (2015) Influence of PE microplastic beads on the uptake and localization of silver in zebrafish (Danio rerio). Environ Pollut 206:73-79

Kim D, Chae Y, An YJ (2017a) Mixture toxicity of nickel and microplastics with different functional groups on Daphnia magna. Environ Sci Technol 51: 12852-12858

Kim MY, Kim C, Moon J, Heo J, Jung SP, Kim JR (2017b) Polymer film-based screening and isolation of polylactic acid (PLA)-degrading microorganisms. J Microbiol Biotechnol 27:342-349

Kleinteich J, Seidensticker S, Marggrander N, Zarfl C (2018) Microplastics reduce short-term effects of environmental contaminants. Part ii: PE particles decrease the effect of polycyclic aromatic hydrocarbons on microorganisms. Int J Environ Res Public Health 15:E287

Koelmans AA, Bakir A, Burton GA, Janssen CR (2016) Microplastic as a vector for chemicals in the aquatic environment: critical review and model-supported reinterpretation of empirical studies. Environ Sci Technol 50:3315-3326

Koelmans AA, Besseling E, Foekema EM (2014) Leaching of plastic additives to marine organisms. Environ Pollut 187:49-54

Koelmans AA, Besseling E, Wegner A, Foekema EM (2013) Plastic as a carrier of POPs to aquatic organisms: a model analysis. Environ Sci Technol 47:7812-7820

Koelmans AA, Brendo M, Thijs M, Jonker MTO (2009) Attenuation of polychlorinated biphenyl sorption to charcoal by humic acids. Environ Sci Technol 43:736-742

Kokalj AJ, Kunej U, Skalar T (2018) Screening study of four environmentally relevant microplastic pollutants: uptake and effects on Daphnia magna and Artemia franciscana. Chemosphere 208:522-529

Kole PJ, Löhr AJ, Van Belleghem F, Ragas A (2017) Wear and tear of tyres: a stealthy source of microplastics in the environment. Int J Environ Res Public Health 14:1265

Koongolla JB, Andrady AL, Kumara PTP, Gangabadage CS (2018) Evidence of microplastics pollution in coastal beaches and waters in southern Sri Lanka. Mar Pollut Bull 137:277-284

Kwon JH, Chang S, Hong SH, Shim WJ (2017) Microplastics as a vector of hydrophobic contaminants: importance of hydrophobic additives. Integr Environ Assess Manag 13:494-499

Lambert S, Sinclair C, Boxall A (2014) Occurrence, degradation, and effect of polymer-based materials in the environment. In: Whitacre DM (ed) Reviews of environmental contamination and toxicology 227. Springer, Switzerland

Lambert S, Sinclair CJ, Bradley EL, Boxall A (2013) Effects of environmental conditions on latex degradation in aquatic systems. Sci Total Environ 447: 225-234

Law KL, Morét-Ferguson S, Maximenko NA, Proskurowski G, Peacock EE, Hafner J, Reddy CM (2010) Plastic accumulation in the North Atlantic subtropical gyre. Science 329:1185-1188

Lebreton L, Andrady A (2019) Future scenarios of global plastic waste generation and disposal. Palgrave Commun 5:6

Lee H, Lee HJ, Kwon JH (2019) Estimating microplastic-bound intake of hydrophobic organic chemicals by fish using measured desorption rates to artificial gut fluid. Sci Total Environ 651:162-170

Lei L, Wu S, Lu S, Liu M, Song Y, Fu Z, Shi H, Raley-Susman KM, He D (2018) Microplastic particles cause intestinal damage and other adverse effects in zebrafish Danio rerio and nematode Caenorhabditis elegans. Sci Total Environ 619:1-8

Leroueil PR, Berry SA, Duthie K, Han G, Rotello VM, McNerny DQ, Baker JR Jr, Orr BG, Holl MM (2008) Wide varieties of cationic nanoparticles induce defects in supported lipid bilayers. Nano Lett 8:420-424

Li J, Zhang K, Zhang H (2018b) Adsorption of antibiotics on microplastics. Environ Pollut 237:460-467

Li X, Chen L, Mei Q, Dong B, Dai X, Ding G, Zeng EY (2018a) Microplastics in sewage sludge from the wastewater treatment plants in China. Water Res 142:75-85

Li Y, Zhang H, Tang C (2020) A review of possible pathways of marine microplastics transport in the ocean. Anthropocene Coasts 3:6-13

Liao Y, Yang J (2020) Microplastic serves as a potential vector for $\mathrm{Cr}$ in an in-vitro human digestive model. Sci Total Environ 703:134805
Lin W, Jiang R, Xiong Y, Wu J, Xu J, Zheng J, Zhu F, Ouyang G (2019) Quantification of the combined toxic effect of polychlorinated biphenyls and nano-sized polystyrene on Daphnia magna. J Hazard Mater 364:531536

Liu G, Zhu Z, Yang Y, Sun Y, Yu F, Ma J (2018) Sorption behavior and mechanism of hydrophilic organic chemicals to virgin and aged microplastics in freshwater and seawater. Environ Pollut 246:26-33

Liu J, Zhang T, Tian L, Liu X, Qi Z, Ma Y, Ji R, Chen W (2019a) Aging significantly affects mobility and contaminant-mobilizing ability of nanoplastics in saturated loamy sand. Environ Sci Technol 53:5805-5815

Liu K, Wang XH, Fang T, Xu P, Zhu LX, Li DJ (2019b) Source and potential risk assessment of suspended atmospheric microplastics in Shanghai. Sci Total Environ 675:462-471

Liu L, Fokkink R, Koelmans AA (2016) Sorption of polycyclic aromatic hydrocarbons to polystyrene nanoplastic. Environ Toxicol Chem 35:16501655

Liu X, Shi H, Xie B, Dionysiou DD, Zhao Y (2019c) Microplastics as both a sink and a source of Bisphenol a in the marine environment. Environ Sci Technol 5: 10188-10196

Liu X, Xu J, Zhao Y, Shi H, Huang CH (2019d) Hydrophobic sorption behaviors of 17 beta-estradiol on environmental microplastics. Chemosphere 226:726-735

Llorca M, Schirinzi G, Martínez M, Barceló D, Farré M (2018) Adsorption of perfluoroalkyl substances on microplastics under environmental conditions. Environ Pollut 235:680-691

Lohmann R (2017) Microplastics are not important for the cycling and bioaccumulation of organic pollutants in the oceans-but should microplastics be considered POPs themselves? Integr Environ Assess Manag 13:460-465

Lu Y, Zhang Y, Deng Y, Jiang W, Zhao Y, Geng J, Ding L, Ren H (2016) Uptake and accumulation of polystyrene microplastics in zebrafish (Danio rerio) and toxic effects in liver. Environ Sci Technol 50:4054-4060

Lusher A, Milian GH, O'Brien J, Berrow S, O'Connor I, Officer R (2015) Microplastic and macroplastic ingestion by a deep diving, oceanic cetacean: the True's beaked whale Mesoplodon Mirus. Environ Pollut 199:85-191

Lusher AL, McHugh M, Thompson RC (2013) Occurrence of microplastics in the gastrointestinal tract of pelagic and demersal fish from the English Channel. Mar Pollut Bull 67:94-99

Lwanga E, Thapa B, Yang X, Gertsen H, Salanki T, Geissen V, Garbeva P (2018) Decay of low-density polyethylene by bacteria extracted from earthworm's guts: a potential for soil restoration. Sci Total Environ 624:753-757

Ma H, Pu S, Liu S, Bai Y, Mandal S, Xing B (2020a) Microplastics in aquatic environments: toxicity to trigger ecological consequences. Environ Pollut 261:114089

Ma J, Ma Y, Yu F, Dai X (2018) Rotating magnetic field-assisted adsorption mechanism of pollutants on mechanically strong sodium alginate/graphene/ L-cysteine beads in batch and fixed-bed column systems. Environ Sci Technol 52:13925-13934

Ma J, Sun Y, Zhang M, Yang M, Gong X, Yu F, Zheng J (2017) Comparative study of graphene hydrogels and aerogels reveals the important role of buriedwater in pollutant adsorption. Environ Sci Technol 51:12283-12292

Ma Y, Huang A, Cao S, Sun F, Wang L, Guo H, Ji R (2016) Effects of nanoplastics and microplastics on toxicity, bioaccumulation, and environmental fate of phenanthrene in fresh water. Environ Pollut 219:166-173

Ma ZF, Ibrahim YS, Lee YY (2020b) Microplastic pollution and health and relevance to the Malaysia's roadmap to zero single-use plastics 2018-2030. Malays J Med Sci 27:1-6

Magara G, Elia AC, Syberg K, Khan FR (2018) Single contaminant and combined exposures of PE microplastics and fluoranthene: accumulation and oxidative stress response in the blue mussel, Mytilus edulis. J Toxicol Environ Health A $81: 1-13$

Martin OV, Voulvoulis N (2009) Sustainable risk management of emerging contaminants in municipal wastewaters. Philos Trans Royal Soc A Math Phys Eng Sci 367:3895-3922

Mata MT, Luza MF, Riquelme CE (2017) Production of diatom-bacteria biofilm isolated from Seriola lalandi cultures for aquaculture application. Aquac Res 48:4308-4320

Mato Y, Isobe T, Takada H, Kanehiro H, Ohtake C, Kaminuma T (2001) Plastic resin pellets as a transport medium for toxic chemicals in the marine environment. Environ Sci Technol 35:318-324 
Mattsson K, Ekvall MT, Hansson LA, Linse S, Malmendal A, Cedervall T (2014) Altered behavior, physiology, and metabolism in fish exposed to polystyrene nanoparticles. Environ Sci Technol 49:553-561

Maximenko N, Hafner J, Niier P (2012) Pathways of marine debris derived from trajectories of Lagrangian drifters. Mar Pollut Bull 65:51-62

Mazurais D, Ernande B, Quazuguel P, Severe A, Huelvan C, Madec L, Mouchel O, Soudant P, Robbens J, Huvet A, Zambonino-Infante J (2015) Evaluation of the impact of PE microbeads ingestion in European sea bass (Dicentrarchus labrax) larvae. Mar Environ Res 112:78-85

McEachern K, Alegria H, Kalagher AL, Hansen C, Morrison S, Hastings D (2019) Microplastics in Tampa Bay, Florida: abundance and variability in estuarine waters and sediments. Mar Pollut Bull 148:97-106

Mohan AJ, Sekhar VC, Bhaskar T, Nampoothiri KM (2016) Microbial assisted high impact polystyrene (HIPS) degradation. Bioresour Technol 213:204-207

Moura V, Ribeiro I, Moriggi P, Capao A, Salles C, Bitati S, Procopio L (2018) The influence of surface microbial diversity and succession on microbiologically influenced corrosion of steel in a simulated marine environment. Arch Microbiol 200:1447-1456

Munier B, Bendell LI (2018) Macro and micro plastics sorb and desorb metals and act as a point source of trace metals to coastal ecosystems. PLoS One 13: e0191759

Naidu SA, Ranga Rao V, Ramu K (2018) Microplastics in the benthic invertebrates from the coastal waters of Kochi, southeastern Arabian Sea. Environ Geochem Health 40:1377-1383

Nakki P, Setala O, Lehtiniemi M (2017) Bioturbation transports secondary microplastics to deeper layers in soft marine sediments of the northern Baltic Sea. Mar Pollut Bull 119:255-261

Nel HA, Froneman PW (2015) A quantitative analysis of microplastic pollution along the south-eastern coastline of South Africa. Mar Pollut Bull 101:274-279

Nelms SE, Galloway TS, Godley BJ, Jarvis DS, Lindeque PK (2018) Investigating microplastic trophic transfer in marine top predators. Environ Pollut 238:999_ 1007

Neufeld L, Stassen F, Sheppard R, Gilman T (2016) The new plastics economy rethinking the future of plastics. World economic forum, Ellen MacArthur Foundation, McKinsey \& Company http://www.ellenmacarthurfoundation. org/publications

Ngo PL, Pramanik BK, Shah K, Roychand R (2019) Pathway, classification and removal efficiency of microplastics in wastewater treatment plants. Environ Pollut 255:113326

Nie H, Wang J, Xu K, Huang Y, Yan M (2019) Microplastic pollution in water and fish samples around Nanxun reef in Nansha Islands, South China Sea. Sci Total Environ 696:134022

Nor NHM, Koelmans AA (2019) Transfer of PCBs from microplastics under simulated gut fluid conditions is biphasic and reversible. Environ Sci Technol 53(4):1874-1883

Obbard RW (2018) Microplastics in polar regions: the role of long range transport. Curr Opin Environ Sci Health 1:24-29

Oberbeckmann S, Kreikemeyer B, Labrenz M (2018) Environmental factors support the formation of specific bacterial assemblages on microplastics. Front Microbiol 8:2709

Oberbeckmann S, Labrenz M (2020) Marine microbial assemblages on microplastics: diversity, adaptation, and role in degradation. Annu Rev Mar Sci 12:209-232

O'Donovan S, Mestre NC, Abel S, Fonseca TG, Carteny CC, Cormier B, Keiter SH, Bebianno MJ (2018) Ecotoxicological effects of chemical contaminants adsorbed to microplastics in the clam Scrobicularia plana. Front Mar Sci 5:143

Ogonowski M, Wenman V, Danielsson S, Gorokhova E (2017) Ingested microplastic is not correlated to HOC concentrations in Baltic Sea herring. CEST [internet]. Rhodes, Greece

Oliveira M, Ribeiro A, Hylland K, Guilhermino L (2013) Single and combined effects of microplastics and pyrene on juveniles ( $0+$ group) of the common goby Pomatoschistus microps (Teleostei Gobiidae). Ecol Indic 34:641-647

Omenn GS, Merchant J, Boatman E, Dement JM, Kuschner M, Nicholson W, Peto J, Rosenstock $L$ (1986) Contribution of environmental fibers to respiratory cancer. Environ Health Perspect 70:51-56

Ory NC, Sobral P, Ferreira JL, Thiel M (2017) Amberstripe scad Decapterus muroadsi (Carangidae) fish ingest blue microplastics resembling their copepod prey along the coast of Rapa Nui (Easter Island) in the South Pacific subtropical gyre. Sci Total Environ 586:430-437
Paco A, Duarte K, da Costa JP, Santos PSM, Pereira R, Pereira ME, Freitas AC, Duarte AC, Rocha-Santos TAP (2017) Biodegradation of polyethylene microplastics by the marine fungus Zalerion maritimum. Sci Total Environ 586:10-15

Park SY, Kim CG (2019) Biodegradation of micro-polyethylene particles by bacterial colonization of a mixed microbial consortium isolated from a landfill site. Chemosphere 222:527-533

Pascall MA, Zabik ME, Zabik MJ, Hernandez RJ (2005) Uptake of polychlorinated biphenyls (PCBs) from an aqueous medium by PE, PVC, and polystyrene films. J Agric Food Chem 53:164

Paul-Pont I, Lacroix C, Fernandez GC, Hegaret H, Lambert C, Le Goïc N, Frere L, Cassone AL, Sussarellu R, Fabioux C, Guyomarch J, Albentosa M, Huvet A, Soudant $P$ (2016) Exposure of marine mussels Mytilus spp. to polystyrene microplastics: toxicity and influence on fluoranthene bioaccumulation. Environ Pollut 216:724-737

Pauly JL, Stegmeier SJ, Allaart HA, Cheney RT, Zhang PJ, Mayer AG, Streck RJ (1998) Inhaled cellulosic and plastic fibers found in human lung tissue. Cancer Epidemiol Biomark Prev 7:419-428

Peda C, Caccamo L, Fossi MC, Gai F, Andaloro F, Genovese L, Perdichizzi A, Romeo T, Maricchiolo G (2016) Intestinal alterations in European sea bass Dicentrarchus labrax (Linnaeus 1758) exposed to microplastics: preliminary results. Environ Pollut 212:251-256

Peters CA, Thomas PA, Rieper KB, Bratton SP (2017) Foraging preferences influence microplastic ingestion by six marine fish species from the Texas Gulf Coast. Mar Pollut Bull 124:82-88

PlasticsEurope (2017) Plastics - the facts 2017. An analysis of European plastics production, demand and waste data. PlasticsEurope Retrieved from https:// www.plasticseurope.org/en/resources/publications/274-plastics-facts-2017 Accessed on 17 August 2020

PlasticsEurope (2019) Plastics - the facts 2019. An analysis of European plastics production, demand and waste data. PlasticsEurope Retrieved from https:// www.plasticseurope.org/en/resources/publications/1804-plastics-facts-2019 Accessed on 17 August 2020

Porter DW, Castranova V, Robinson VA, Hubbs AF, Mercer RR, Scabilloni J, Goldsmith T, Schwegler-Berry D, Battelli L, Washko R, Burkhart J, Piacitelli C, Whitmer M, Jones W (1999) Acute inflammatory reaction in rats after intratracheal instillation of material collected from a nylon flocking plant. J Toxicol Environ Health, Part A 57:25-45

Prata JC, Lavorante BRBO, Conceição M, Montenegro BSM, Guilhermino L (2018) Influence of microplastics on the toxicity of the pharmaceuticals procainamide and doxycycline on the marine microalgae Tetraselmis chuii. Aquat Toxicol 197:143-152

Prokic MD, Radovanović TB, Gavrić JP, Faggio C (2019) Ecotoxicological effects of microplastics: examination of biomarkers, current state and future perspectives. TrAC Trends Anal Chem 111:37-46

Qi X, Ren Y, Wang X (2017) New advances in the biodegradation of poly (lactic) acid. Int Biodeterior Biodegradation 117:215-223

Qiao R, Lu K, Deng Y, Ren H, Zhang Y (2019) Combined effects of polystyrene microplastics and natural organic matter on the accumulation and toxicity of copper in zebrafish. Sci Total Environ 682:128-137

Qu H, Ma R, Wang B, Zhang Y, Yin L, Yu G, Deng S, Huang J, Wang Y (2018) Effects of microplastics on the uptake, distribution and biotransformation of chiral antidepressant venlafaxine in aquatic ecosystem. J Hazard Mater 359:104-112

Raju S, Carbery M, Kuttykattil A, Senathirajah K, Subashchandrabose SR, Evans G, Thavamani $P$ (2018) Transport and fate of microplastics in wastewater treatment plants: implications to environmental health. Rev Environ Sc Biotechnol 17:637-653

Rehse S, Kloas W, Zarfl C (2018) Microplastics reduce short-term effects of environmental contaminants. Part I: effects of bisphenol a on freshwater zooplankton are lower in presence of PA particles. Int J Environ Res Public Health 15:280

Rieux AD, Ragnarsson EGE, Gullberg E, Préat V, Schneider YJ, Artursson P (2005) Transport of nanoparticles across an in vitro model of the human intestinal follicle associated epithelium. Eur J Pharm Sci 25:455-465

Rios LM, Moore C, Jones PR (2007) Persistent organic pollutants carried by synthetic polymers in the ocean environment. Mar Pollut Bull 54:1230-1237

Rocha-Santos T, Duarte AC (2015) A critical overview of the analytical approaches to the occurrence, the fate and the behavior of microplastics in the environment. TrAC Trends Anal Chem 65:47-53

Rochman CM (2018) Microplastics research - from sink to source. Science 360: 28-29 
Rochman CM, Hentschel BT, Teh SJ (2014) Long-term sorption of metals is similar among plastic types: implications for plastic debris in aquatic environments. PLoS one:e85433.

Rochman CM, Hoh E, Hentschel BT, Kaye S (2013a) Long-term field measurement of sorption of organic contaminants to five types of plastic pellets: implications for plastic marine debris. Environ Sci Technol 47:1646-1654

Rochman CM, Hoh E, Kurobe T, Teh SJ (2013b) Ingested plastic transfers hazardous chemicals to fish and induces hepatic stress. Sci Rep:3

Rose D, Webber M (2019) Characterization of microplastics in the surface waters of Kingston harbour. Sci Total Environ 664:753-760

Ruiz-Orejón LF, Sardá R, Ramis-Pujol J (2018) Now, you see me: high concentrations of floating plastic debris in the coastal waters of the Balearic Islands (Spain). Mar Pollut Bull 133:636-646

Rujnic-Sokele M, Pilipovic A (2017) Challenges and opportunities of biodegradable plastics: a mini review. Waste Manag Res 35:132-140

Ryan PG (1988) Effects of ingested plastic on seabird feeding: evidence from chickens. Mar Pollut Bull 19:125-128

Ryberg MW, Hauschild MZ, Wang F, Averous-Monnery S, Laurent A (2019) Global environmental losses of plastics across their value chains. Resour Conserv Recycl 151:104459

Saeed T, Al-Jandal N, Al-Mutairi A, Taqi H (2020) Microplastics in Kuwait marine environment: results of first survey. Mar Pollut Bull 152:110880

Saliu F, Montano S, Garavaglia MG, Lasagni M, Seveso D, Galli P (2018) Microplastic and charred microplastic in the Faafu atoll, Maldives. Mar Pollut Bull 136:464-471

Savoca S, Capillo G, Mancuso M, Bottari T, Crupi R, Branca C, Spanò N (2019) Microplastics occurrence in the Tyrrhenian waters and in the gastrointestinal tract of two congener species of seabreams. Environ Toxicol Pharmacol 67: 35-41

Scanes E, Wood H, Ross P (2019) Microplastics detected in haemolymph of the Sydney rock oyster Saccostrea glomerata. Mar Pollut Bull 149:110537

Schönlau C, Karlsson TM, Rotander A, Nilsson H, Engwall M, van Bavel B, Kärrman A (2020) Microplastics in sea-surface waters surrounding Sweden sampled by manta trawl and in-situ pump. Mar Pollut Bull 153:111019

Schwabl P, Köppel S, Königshofer P, Bucsics T, Trauner M, Reiberger T, Liebmann B (2019) Detection of various microplastics in human stool: a prospective case series. Ann Intern Med 171:453-457

Scopetani C, Cincinelli A, Martellini T, Lombardini E, Ciofini A, Fortunati A, Pasquali V, Ciattini S, Ugolini A (2018) Ingested microplastic as a two-way transporter for PBDEs in Talitrus saltator. Environ Res 167:411-417

Sen SK, Raut S (2015) Microbial degradation of low density polyethylene (LDPE): a review. J Environ Chem Eng 3:462-473

Setala O, Fleming-Lehtinen V, Lehtiniemi M (2014) Ingestion and transfer of microplastics in the planktonic food web. Environ Pollut 185:77-83

Setala O, Norkko J, Lehtiniemi M (2016) Feeding type affects microplastic ingestion in a coastal invertebrate community. Mar Pollut Bull 102:95-101

Shen XC, Li DC, Sima XF, Cheng HY, Jiang H (2018) The effects of environmental conditions on the enrichment of antibiotics on microplastics in simulated natural water column. Environ Res 166:377-383

Sleight VA, Bakir A, Thompson RC, Henry TB (2017) Assessment of microplasticsorbed contaminant bioavailability through analysis of biomarker gene expression in larval zebrafish. Mar Pollut Bull 116:291-297

Song YK, Hong SH, Jang M, Kang JH, Kwon OY, Han GM, Shim WJ (2014) Large accumulation of micro-sized synthetic polymer particles in the sea surface microlayer. Environ Sci Technol 48:9014-9021

Sorb (2020) Dictionary.com Retrieved from https://www.dictionary.com/browse/ sorb Accessed on 17 August 2020.

Sørensen L, Rogers E, Altin D, Salaberria I, Booth AM (2020) Sorption of PAHs to microplastic and their bioavailability and toxicity to marine copepods under co-exposure conditions. Environ Pollut 258:113844

Steinmetz Z, Wollmann C, Schaefer M, Schaefer M, Buchmann C, David J, Troger J, Munoz K, Foro O, Schaumann GE (2016) Plastic mulching in agriculture. Trading short-term agronomic benefits for long-term soil degradation? Sci Total Environ 550:690-705

Stock V, Böhmert L, Lisicki E, Block R, Cara-Carmona J, Pack LK, Selb R, Lichtenstein D, Voss L, Henderson CJ, Zabinsky E, Sieg H, Braeuning A, Lampen A (2019) Uptake and effects of orally ingested polystyrene microplastic particles in vitro and in vivo. Arch Toxicol 93:1817-1833

Su L, Deng H, Li B, Chen Q, Pettigrove V, Wu C, Shi H (2018) The occurrence of microplastic in specific organs in commercially caught fishes from coast and estuary area of East China. J Hazard Mater 365:716-724
Sul JAl, Costa MF (2014) The present and future of microplastic pollution in the marine environment. Environ Pollut 185:352-364

Sun J, Dai X, Wang Q, van Loosdrecht MCM, Ni BJ (2019) Microplastics in wastewater treatment plants: detection, occurrence and removal. Water Res 152:21-37

Sun X, Liang J, Zhu M, Zhao Y, Zhang B (2018) Microplastics in seawater and zooplankton from the Yellow Sea. Environ Pollut 242:585-595

Sutton R, Mason SA, Stanek SK, Willis-Norton E, Wren IF, Box C (2016) Microplastic contamination in the San Francisco Bay, California. USA Mar Poll Bull:230-235

Syberg K, Nielsen A, Khan FR, Banta GT, Palmqvist A, Jepsen PM (2017) Microplastic potentiates triclosan toxicity to the marine copepod Acartia tonsa (Dana). J Toxicol Environ Health 80:1369-1371

Syranidou E, Karkanorachaki K, Amorotti F, Repouskou E, Kroll K, Kolvenbach B, Corvini PF, Fava F, Kalogerakis N (2017) Development of tailored indigenous marine consortia for the degradation of naturally weathered polyethylene films. PLoS One 12:e0183984

Talvitie J, Mikola A, Koistinen A, Setala O (2017) Solutions to microplastic pollution - removal of microplastics from wastewater effluent with advanced wastewater treatment technologies. Water Res 123:401-407

Tan X, Yu X, Cai L, Wang J, Peng J (2019) Microplastics and associated PAHs in surface water from the Feilaixia reservoir in the Beijiang River, China. Chemosphere 221:834-840

Tanaka K, Takada H, Yamashita R, Mizukawa K, Fukuwaka MA, Watanuki Y (2013) Accumulation of plastic-derived chemicals in tissues of seabirds ingesting marine plastics. Mar Pollut Bull 69:219-222

Tanaka K, Takada H, Yamashita R, Mizukawa K, Fukuwaka MA, Watanuki Y (2015) Facilitated leaching of additive-derived PBDEs from plastic by seabirds' stomach oil and accumulation in tissues. Environ Sci Technol 49:1179911807

Tanaka K, Yamashita R, Takada H (2018) Transfer of hazardous chemicals from ingested plastics to higher-trophic-level organisms. In: Takada $\mathrm{H}$, Karapanagioti HK (eds) Hazardous chemicals associated with plastics in the marine environment. The handbook of environmental chemistry, vol 78. Springer, Cham, pp 267-280

Ter HA, Ladirat L, Gendre X, Goudounèche D, Pusineri C, Routaboul C, Tenailleau C, Duployer B, Perez E (2016) Understanding the fragmentation pattern of marine plastic debris. Environ Sci Technol 50:5668

Teuten EL, Rowland SJ, Galloway TS, Thompson RC (2007) Potential for plastics to transport hydrophobic contaminants. Environ Sci Technol 41:7759-7764

Teuten EL, Saquing JM, Knappe DRU, Barlaz MA, Jonsson S, Bjorn A, Rowland SJ, Thompson RC, Galloway TS, Yamashita R, Ochi D, Watanuki Y, Moore C, Viet PH, Tana TS, Prudente M, Boonyatumanond R, Zakaria MP, Akkhavong K, Ogata Y, Hirai H, Iwasa S, Mizukawa K, Hagino Y, Imamura A, Saha M, Takada $H$ (2009) Transport and release of chemicals from plastics to the environment and to wildlife. Philos Trans R Soc B Biol Sci 364:2027-2045

Thompson RC, Moore CJ, vom Saal FS, Swan SH (2009) Plastics, the environment and human health: current consensus and future trends. Philos Trans R Soc 364:2153-2166

Todd G, Wohlers D, Citra M (2003) Agency for toxic substances and disease registry. Atlanta, GA

Tosetto L, Brown C, Williamson JE (2016) Microplastics on beaches: ingestion and behavioral consequences for beachhoppers. Mar Biol 163:199

Tourinho PS, Koci V, Loureiro S, Gestel CAM (2019) Partitioning of chemical contaminants to microplastics: sorption mechanisms, environmental distribution and effects on toxicity and bioaccumulation. Environ Pollut 252: $1246-1256$

Tsang YY, Mak CW, Liebich C, Lam SW, Sze ET, Chan KM (2017) Microplastic pollution in the marine waters and sediments of Hong Kong. Mar Pollut Bull 115:20-28

Tsiota P, Karkanorachaki K, Syranidou E, Franchini M, Kalogerakis N (2018) Microbial degradation of HDPE secondarymicroplastics: preliminary results. Proceedings of the international conference on microplastic pollution in the Mediterranean Sea, pp 181-188

Turner A, Holmes LA (2015) Adsorption of trace metals by microplastic pellets in fresh water. Environ Chem 12:600

Uscategui YL, Arevalo FR, Diaz LE, Cobo MI, Valero MF (2016) Microbial degradation, cytotoxicity and antibacterial activity of polyurethanes based on modified castor oil and polycaprolactone. J Biomater Sci Polym Ed 27:1860-1879

USEPA (2012) Basic information about Di (2-ethylhexyl) phthalate in drinking water. United States Environmental Protection Agency Accessed on 17 
August 2020. Retrieved from http://water.epa.gov/drink/contaminants/ basicinformation/di_2-ethylhexyl_phthalate.cfm

Vajargah MF, Imanpoor MR, Shabani A, Hedayati A, Faggio C (2019) Effect of long-term exposure of silver nanoparticles on growth indices, hematological and biochemical parameters and gonad histology of male goldfish (Carassius auratus Gibelio). Microsc Res Tech 82:1224-1230

Vajargah MF, Yalsuyi AM, Hedayati A, Faggio C (2018) Histopathological lesions and toxicity in common carp (Cyprinus carpio L. 1758) induced by copper nanoparticles. Microsc Res Tech 81:724-729

van der Hal N, Yeruham E, Shukis D, Rilov G, Astrahan P, Angel DL (2020) Uptake and incorporation of PCBs by eastern Mediterranean rabbitfish that consumed microplastics. Mar Pollut Bull 150:110697

Vega RL, Epel D (2004) Stress-induced apoptosis in sea urchin embryogenesis. Mar Environ Res 58:799-802

Velzeboer I, Kwadijk CJAF, Koelmans AA (2014) Strong sorption of PCBs tonanoplastics, microplastics, carbon nanotubes and fullerenes. Environ Sci Technol 48:4869-4876

Veneman WJ, Spaink HP, Brun NR, Bosker T, Vijver MG (2017) Pathway analysis of systemic transcriptome responses to injected polystyrene particles in zebrafish larvae. Aquat Toxicol 190:112-120

Vethaak AD, Leslie HA (2016) Plastic debris is a human health issue. Environ Sci Technol 50:6825-6826

Viršek MK, Lovšin MN, Koren Š, Kržan A, Peterlin M (2017) Microplastics as a vector for the transport of the bacterial fish pathogen species Aeromonas salmonicida. Mar Pollut Bull 125:301-309

Volkheimer G (1975) Hematogenous dissemination of ingested PVC particles. Ann N Y Acad Sci 246:164-171

Vroom RJ, Koelmans AA, Besseling E, Halsband C (2017) Aging of microplastics promotes their ingestion by marine zooplankton. Environ Pollut 231:987-996

Wang F, Shih KM, Li XY (2015) The partition behavior of perfluorooctanesulfonate (PFOS) and perfluorooctanesulfonamide (FOSA) on microplastics. Chemosphere 119:841-847

Wang F, Wong CS, Chen D, Lu X, Wang F, Zeng EY (2018) Interaction of toxic chemicals with microplastics: a critical review. Water Res 139:208-219

Wang J, Liu X, Liu G, Zhang Z, Wu H, Cui B, Bai J, Zhang W (2019) Size effect of polystyrene microplastics on sorption of phenanthrene and nitrobenzene. Ecotoxicol Environ Saf 173:331-338

Wang W, Ge J, Yu X (2020a) Bioavailability and toxicity of microplastics to fish species: a review. Ecotoxicol Environ Saf 189:109913

Wang YL, Lee YH, Chiu IJ, Lin YF, Chiu HW (2020b) Potent impact of plastic nanomaterials and micromaterials on the food chain and human health. Int J Mol Sci 21:1727

Wardrop P, Shimeta J, Nugegoda D, Morrison PD, Miranda A, Tang M, Clarke BO (2016) Chemical pollutants sorbed to ingested microbeads from personal care products accumulate in fish. Environ Sci Technol 50:4037-4044

Weithmann N, Möller JN, Löder MGJ, Piehl S, Laforsch C, Freitag R (2018) Organic fertilizer as a vehicle for the entry of microplastic into the environment. Sci Adv 4

Wen B, Jin SR, Chen ZZ, Gao JZ, Liu YN, Liu JH, Feng XS (2018) Single and combined effects of microplastics and cadmium on the cadmium accumulation, antioxidant defence and innate immunity of the discus fish (Symphysodon aequifasciatus). Environ Pollut 243:462-471

Windsor FM, Tilley RM, Tyler CR, Ormerod SJ (2019) Microplastic ingestion by riverine macroinvertebrates. Sci Total Environ 646:68-74

Wong SL, Nyakuma BB, Wong KY, Lee CT, Lee TH, Lee CH (2020) Microplastics and nanoplastics in global food webs: a bibliometric analysis (2009-2019). Mar Pollut Bull 158:111432

Woodall LC, Sanchez-Vidal A, Canals M, Paterson GL, Coppock R, Sleight V, Calafat A, Rogers AD, Narayanaswamy BE, Thompson RC (2014) The deep sea is a major sink for microplastic debris. R Soc Open Sci 1:140317

Wright SL, Kelly FJ (2017) Plastic and human health: a micro issue? Environ Sci Technol 2017(51):6634-6647

Wright SL, Rowe D, Thompson RC, Galloway TS (2013a) Microplastic ingestion decreases energy reserves in marine worms. Curr Biol 23:R1031-R1033

Wright SL, Thompson RC, Galloway TS (2013b) The physical impacts of microplastics on marine organisms: a review. Environ Pollut 178:483-492

Wu B, Taylor CM, Knappe DR, Nanny MA, Barlaz MA (2001) Factors controlling alkylbenzene sorption to municipal solid waste. Environ Sci Technol 35:45694576

Wu C, Zhang K, Huang X, Liu J (2016) Sorption of pharmaceuticals and personal care products to PE debris. Environ Sci Pollut Res Int 23:8819-8826
Wu WM, Yang J, Criddle CS (2017) Microplastics pollution and reduction strategies. Front Environ Sci Eng 11:6

Xia Y, Zhou J, Gong Y, Li Z, Zeng EY (2020) Strong influence of surfactants on virgin hydrophobic microplastics adsorbing ionic organic pollutants. Environ Pollut 265:115061

Yamashita R, Tanimura A (2007) Floating plastic in the Kuroshio current area, western North Pacific Ocean. Mar Pollut Bull 54:485-488

Yang D, Shi H, Li L, Li J, Jabeen K, Kolandhasamy P (2015a) Microplastic pollution in table salts from China. Environ Sci Technol 49:13622-13627

Yang Y, Yang J, Wu WM, Zhao J, Song Y, Gao L, Yang R, Jiang L (2015b) Biodegradation and mineralization of polystyrene by plastic-eating mealworms: part 1. Chemical and physical characterization and isotopic tests. Environ Sci Technol 49:12080-12086

Yeo BG, Takada H, Yamashita R, Okazaki Y, Uchida K, Tokai T, Tanaka K, Trenholm N (2020) PCBs and PBDEs in microplastic particles and zooplankton in open water in the Pacific Ocean and around the coast of Japan. Mar Pollut Bull 151:110806

Yin L, Chen B, Xia B, Shi X, Qu K (2018) Polystyrene microplastics alter the behavior, energy reserve and nutritional composition of marine jacopever (Sebastes schlegelii). J Hazard Mater 360:97-105

Yoshida S, Hiraga K, Takehana T, Taniguchi I, Yamaji H, Maeda Y, Toyohara K, Miyamoto K, Kimura Y, Oda K (2016) A bacterium that degrades and assimilates poly (ethylene terephthalate). Science 351:1196-1199

Yu F, Sun Y, Yang M, Ma J (2019b) Adsorption mechanism and effect of moisture contents on ciprofloxacin removal by three-dimensional porous graphene hydrogel. J Hazard Mater 374:195-202

Yu F, Yang C, Zhu Z, Bai X, Ma J (2019a) Adsorption behavior of organic pollutants and metals on micro/nanoplastics in the aquatic environment. Sci Total Environ 694:133643

Yu X, Ladewig S, Bao S, Toline CA, Whitmire S, Chow AT (2018) Occurrence and distribution of microplastics at selected coastal sites along the southeastern United States. Sci Total Environ 613-614:298-305

Yuan J, Ma J, Sun Y, Zhou T, Zhao Y, Yu F (2020) Microbial degradation and other environmental aspects of microplastics/plastics. Sci Total Environ 715:136968

Zettler ER, Mincer TJ, Amaral-Zettler LA (2013) Life in the "plastisphere": microbial communities on plastic marine debris. Environ Sci Technol 47:7137-7146

Zhan Z, Wang J, Peng J, Xie Q, Huang Y, Gao Y (2016) Sorption of 3,3',4,4'tetrachlorobiphenyl by microplastics: a case study of PP. Mar Pollut Bull 110:559-563

Zhang F, Man YB, Mo Y, Man KY, Wong MH (2019a) Direct and indirect effects of microplastics on bivalves, with a focus on edible species: a mini-review. Crit Rev Environ Sci Technol:1-35

Zhang H (2017) Transport of microplastics in coastal seas. Estuar Coast Shelf Sci 199:74-86

Zhang H, Fei Y, Wang H, Chen Y, Huang S, Yu B, Wang J, Tong Y, Wen D, Zhou B, He X, Xia X, Luo Y (2020a) Interaction of microplastics and organic pollutants: quantification, environmental fates, and ecological consequences. In: He D, Luo Y (eds) Microplastics in terrestrial environments - emerging contaminants and major challenges. The handbook of environmental chemistry. Springer, Heidelberg, pp 1-24

Zhang S, Ding J, Razanajatovo RM, Jiang H, Zou H, Zhu W (2019b) Interactive effects of polystyrene microplastics and roxithromycin on bioaccumulation and biochemical status in the freshwater fish red tilapia (Oreochromis niloticus). Sci Total Environ 648:1431-1439

Zhang W, Zhang S, Wang J, Wang Y, Mu J, Wang P, Ma D (2017) Microplastic pollution in the surface waters of the Bohai Sea, China. Environ Pollut 231: 541-548

Zhang X, Chen J, Li J (2020b) The removal of microplastics in the wastewater treatment process and their potential impact on anaerobic digestion due to pollutants association. Chemosphere 251:126360

Zhang Z, Chen Y (2020) Effects of microplastics on wastewater and sewage sludge treatment and their removal: a review. Chem Eng J 382:122955

Zhao S, Zhu L, Wang T, Li D (2014) Suspended microplastics in the surface water of the Yangtze estuary system, China: first observations on occurrence, distribution. Mar Pollut Bull 86:562-568

Zhao SY, Danley M, Ward JE, Li DJ, Mincer TJ (2017) An approach for extraction, characterization and quantitation of microplastic in natural marine snow using Raman microscopy. Anal Methods 9:1470-1478

Zhao SY, Ward JE, Danley M, Mincer TJ (2018) Field-based evidence for microplastic in marine aggregates and mussels: implications for trophic transfer. Environ Sci Technol 52:11038-11048 
Zheng Y, Li J, Cao W, Liu X, Jiang F, Ding J, Sun C (2019) Distribution characteristics of microplastics in the seawater and sediment: a case study in Jiaozhou Bay, China. Sci Total Environ 674:27-35

Zhu D, Chen Q, An X, Yang X, Christie P, Ke X, Wu L, Zhu Y (2018a) Exposure of soil collembolans to microplastics perturbs their gut microbiota and alters their isotopic composition. Soil Biol Biochem 116:302-310

Zhu J, Zhang Q, Li Y, Tan S, Kang Z, Yu X, Shi H (2019) Microplastic pollution in the Maowei Sea, a typical mariculture bay of China. Sci Total Environ 658:62-68

Zhu L, Bai H, Chen B, Sun X, Qu K, Xia B (2018b) Microplastic pollution in North Yellow Sea, China: observations on occurrence, distribution and identification. Sci Total Environ 636:20-29

Ziajahromi S, Kumar A, Neale PA, Leusch FD (2019) Effects of PE microplastics on the acute toxicity of a synthetic pyrethroid to midge larvae (Chironomus tepperi) in synthetic and river water. Sci Total Environ 671:971-975

Zuo LZ, Li HX, Lin L, Sun YX, Diao ZH, Liu S, Zhang ZY, Xu XR (2019) Sorption and desorption of phenanthrene on biodegradable poly (butylene adipate co-terephtalate) microplastics. Chemosphere 215:25-32

\section{Publisher's Note}

Springer Nature remains neutral with regard to jurisdictional claims in published maps and institutional affiliations.

\section{Submit your manuscript to a SpringerOpen ${ }^{\circ}$ journal and benefit from:}

- Convenient online submission

- Rigorous peer review

- Open access: articles freely available online

- High visibility within the field

- Retaining the copyright to your article

Submit your next manuscript at $\boldsymbol{\nabla}$ springeropen.com 